\title{
DISPLACEMENT DUCTILITY AND ENERGY ASSESSMENT FROM SHAKING TABLE TESTS ON RC STRUCTURAL WALLS
}

\author{
Pierino Lestuzzi ${ }^{\mathrm{a},}$, Hugo Bachmann ${ }^{\mathrm{b}}$ \\ ${ }^{\text {a } I S-S t r u c t u r a l ~ E n g i n e e r i n g ~ I n s t i t u t e, ~ E P F L-E c o l e ~ P o l y t e c h n i q u e ~ F e ́ d e ́ r a l e ~ d e ~ L a u s a n n e ~}$ \\ ${ }^{*}$ Corresponding address: \\ EPFL ENAC IS IMAC, Bâtiment GC, Station 18, CH-1015 Lausanne, Switzerland. \\ Phone: +41 2169363 62; fax: +41 2169347 48; E-mail address: pierino.lestuzzi@epfl.ch \\ ${ }^{b}$ former: IBK-Institute of Structural Engineering, ETHZ-Swiss Federal Institute of Technology, Zurich
}

\begin{abstract}
Dynamic tests on six reinforced concrete structural walls on the ETH earthquake simulator have generated many new opportunities for assessment of seismic behavior and energy. After a brief outline of the tests, this paper describes an investigation involving an experimental determination of yield displacement, displacement ductility and energy content of the walls during the tests. Yield displacement is directly obtained from measurements. Measured results correspond well to calculated predictions. Moreover, displacement ductilities reached during the tests coincide with design assumptions. Input, kinetic and dissipated energies (through friction, viscous damping and plastic deformations) are also determined from measurements. Variations in the distribution of the energy dissipated by plastic deformations (hysteretic energy) at the wall base are related to the good and poor seismic behavior of the walls observed during the tests. A dissipation of the energy concentrated in the first crack at the wall base leads to poor seismic behavior. The ratio of hysteretic energy to the total dissipated energy (friction+viscous+hysteretic) remains almost constant.
\end{abstract}

KEYWORDS: seismic behavior, shaking table tests, reinforced concrete structural wall, yield displacement, ductility, energy

\section{Introduction}

As part of the research project "Reinforced concrete structures under cyclic dynamic and cyclic static actions", six reinforced concrete structural walls were tested on the ETH earthquake simulator at the Institute of Structural Engineering (IBK) of the Swiss Federal Institute of Technology (ETH) in Zurich, Switzerland. The objective of the project was to analyse the dynamic plastic behavior of reinforced concrete slender structural walls subjected to earthquake ground motions. The tests were intended to calibrate input parameters of numerical models and to check design rules of structural walls. The "raw" results of the dynamic tests ${ }^{1)}$ are published in [1] and [2] and related interpretations are published in [3], [4] and [5]. This paper addresses dynamic tests and multi-degree-of-freedom systems.

The paper begins with a summary of the tests performed and selected interpretations of results are examined. Challenges associated with experimental determination of the yield displacement for a multi-degree-of-freedom system are considered initially, after which the energy content of the walls during the tests is determined from the measurements and plotted. Two parameters, the time at which the bulk of the energy was introduced and the distribution of the hysteretic energy at the wall base (distribution of plastic deformations), are of particular interest. These results are compared with observations related to the seismic behavior of the wall.

\footnotetext{
1) All test data are collected on a CD which may be obtained from the authors.
} 


\section{Summary of the dynamic tests}

The six test walls, labelled WDH1 to WDH6, were scaled at 1:3, representing the structural walls of a three-story prototype building as shown in Fig. 1 (left). The prototype building is a typical structural wall system consisting of flat slabs, small columns designed for gravity loads only and a few relatively slender structural walls of rectangular cross section.

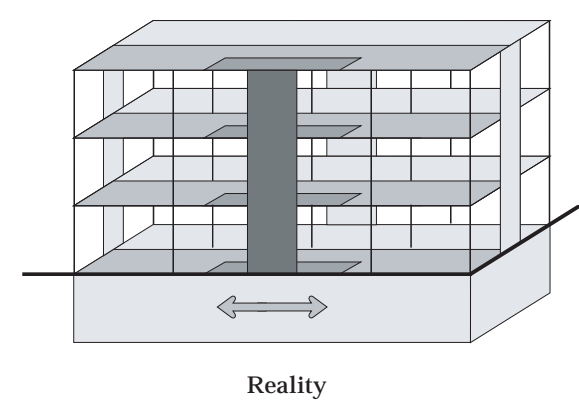

3-storey building with RC structural walls

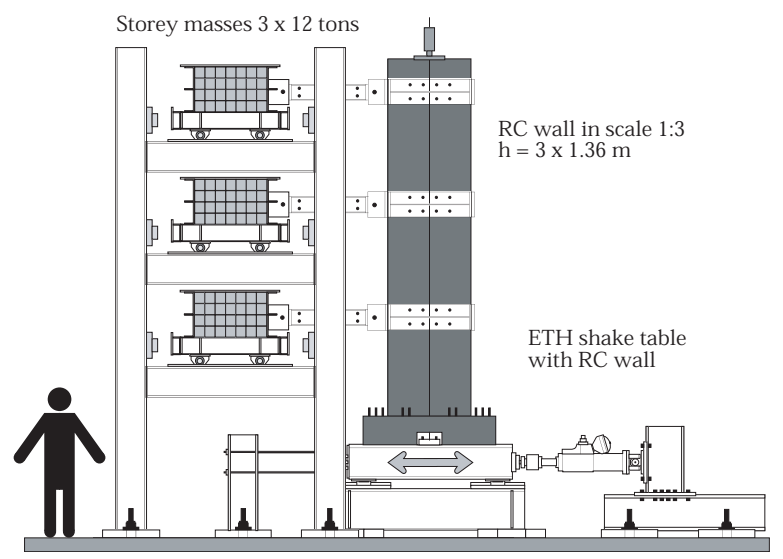

Fig. 1. Prototype building with reinforced concrete structural wall system (left) and the corresponding test set-up in scale 1:3 with reinforced concrete test wall (right).

Based on experiences during initial tests with smaller storey masses directly attached to the walls [6], a separate test set-up was developed with three horizontally moveable masses attached to the wall by pinned steel struts (Fig. 1 right). In this way, a realistic relation between tributary areas of gravity loads and horizontal inertial forces respectively, according to the prototype building, could be obtained. This test set-up thus permitted a nearly perfect simulation of the prototype building. Only the favourable and relatively small stiffness resulting from the frame effect of the slabs and columns with the structural walls in the real building was neglected. The axial force due to gravity loads at the wall base (plastic region) was applied by external posttensioning. Synthetic spectrum-compatible earthquakes were used for ground motion. Each wall was tested by different series of earthquakes up to failure.

\section{1 Test walls}

The test walls were rectangular in cross section with the following dimensions: horizontal wall length $\mathrm{l}_{\mathrm{w}}=1.00$ or $0.90 \mathrm{~m}$, wall width $\mathrm{b}_{\mathrm{w}}=0.10 \mathrm{~m}$ and total height including footing $\mathrm{h}_{\text {tot }}=4.65 \mathrm{~m}$. The main structural characteristics of the test walls are summarized in Table 1.

The concrete dimensions and the reinforcement were chosen considering the available bending moment reaction capacity of the earthquake simulator [7]. The scale 1:3 enables the use of ordinary reinforcing steel with diameters of $\varnothing 4.2$ to $\varnothing 8 \mathrm{~mm}$ and cement paste concrete with a maximum aggregate diameter of $16 \mathrm{~mm}$. A special high ductility steel was used for the reinforcement bars with diameters of $\varnothing 5.2 \mathrm{~mm}$. The main characteristics of the materials are summarized in Table 2. The test parameters included the earthquake ground motion (for different soil conditions and intensities), the ductility properties of the reinforcing steel, the design method (capacity design for limited ductility and conventional design) and the reinforcement ratio (total vertical reinforcement between $0.47 \%$ and $0.60 \%$ ). The axial force was equal to $3 \%$ of the resistance of the gross section $\left(0.03 \mathrm{~A}_{\mathrm{c}} \mathrm{f}_{\mathrm{c}}\right)$ for all walls and the maximum nominal shear stress was between $0.74 \mathrm{MPa}$ and $0.93 \mathrm{MPa}$. 
Table 1

Main structural characteristics of the test walls [1]

\begin{tabular}{cccccccccc}
\hline Wall & $\begin{array}{c}1_{\mathrm{w}} \\
{[\mathrm{m}]}\end{array}$ & $\begin{array}{c}\mathrm{b}_{\mathrm{w}} \\
{[\mathrm{m}]}\end{array}$ & $\begin{array}{c}\varnothing_{\text {end }}{ }^{\mathrm{a}} \\
{[\mathrm{mm}]}\end{array}$ & $\begin{array}{c}\oint_{\text {web }}{ }^{\mathrm{b}} \\
{[\mathrm{mm}]}\end{array}$ & $\begin{array}{c}\rho_{\text {end }}{ }^{\mathrm{c}} \\
{[\%]}\end{array}$ & $\begin{array}{c}\rho_{\text {web }}{ }^{\mathrm{d}} \\
{[\%]}\end{array}$ & $\begin{array}{c}\rho_{\text {tot }}{ }^{\mathrm{e}} \\
{[\%]}\end{array}$ & $\begin{array}{c}\mathrm{s}_{\text {end }}{ }^{\mathrm{f}} \\
{[\mathrm{mm}]}\end{array}$ & $\begin{array}{c}\mathrm{S}_{\text {end }} / \varrho_{\text {end }} \\
{[-]}\end{array}$ \\
\hline WDH1 & 1.00 & 0.10 & 6.0 & 4.2 & 0.71 & 0.32 & 0.51 & 45 & 7.5 \\
WDH2 & 1.00 & 0.10 & 6.0 & 4.2 & 0.71 & 0.32 & 0.51 & 45 & 7.5 \\
WDH3 & 0.90 & 0.10 & 5.2 & 5.2 & 0.73 & 0.42 & 0.47 & 40 & 7.7 \\
WDH4 & 0.90 & 0.10 & 5.2 & 5.2 & 0.73 & 0.42 & 0.47 & 40 & 7.7 \\
WDH5 & 0.90 & 0.10 & 8.0 & 5.2 & 1.72 & 0.42 & 0.60 & 100 & 12.5 \\
WDH6 & 0.90 & 0.10 & 8.0 & 5.2 & 1.72 & 0.42 & 0.60 & 60 & 7.5 \\
\hline
\end{tabular}

${ }^{a} \emptyset_{\text {end }}$ : diameter of the vertical reinforcement in the boundary region of the wall

${ }^{b} \emptyset_{\text {web }}$ : diameter of the vertical reinforcement in the web region of the wall

${ }^{c} \rho_{\text {end }}$ : vertical reinforcement ratio in the boundary region of the wall

${ }^{\mathrm{d}} \rho_{\text {web }}$ : vertical reinforcement ratio in the web region of the wall

${ }^{e} \rho_{\text {tot: }}$ total vertical reinforcement ratio

${ }^{{ }^{\mathrm{S}}} \mathrm{S}_{\text {end }}$ : vertical spacing of the stabilizing horizontal reinforcement in the boundary region of the wall

Table 2

Main material characteristics of the test walls [1]

\begin{tabular}{ccccccccc}
\hline Wall & $\begin{array}{c}\sigma_{\text {end }} \\
{[\mathrm{mm}]}\end{array}$ & $\begin{array}{c}\mathrm{R}_{\mathrm{m}}{ }^{\mathrm{a}} \\
{[\mathrm{MPa}]}\end{array}$ & $\begin{array}{c}\mathrm{R}_{\mathrm{p} 0.2}{ }^{\mathrm{b}} \\
{[\mathrm{MPa}]}\end{array}$ & $\begin{array}{c}\mathrm{R}_{\mathrm{m}} / \mathrm{R}_{\mathrm{p} 0.2}{ }^{\mathrm{c}} \\
{[-]}\end{array}$ & $\begin{array}{c}\mathrm{A}_{\mathrm{gt}}{ }^{\mathrm{d}} \\
{[\%]}\end{array}$ & $\begin{array}{c}\mathrm{E}_{\mathrm{s}}{ }^{\mathrm{e}} \\
{[\mathrm{GPa}]}\end{array}$ & $\begin{array}{c}\mathrm{f}_{\mathrm{c}}{ }^{\mathrm{f}} \\
{[\mathrm{MPa}]}\end{array}$ & $\begin{array}{c}\mathrm{E}_{\mathrm{c}}{ }^{\mathrm{g}} \\
{[\mathrm{GPa}]}\end{array}$ \\
\hline WDH1 & 6.0 & 549.2 & 501.1 & 1.10 & 4.9 & 206.7 & 39.7 & 34.2 \\
WDH2 & 6.0 & 550.0 & 503.1 & 1.09 & 4.8 & 207.5 & 40.4 & 36.7 \\
WDH3 & 5.2 & 583.7 & 474.2 & 1.23 & 6.2 & 215.7 & 36.5 & 32.7 \\
WDH4 & 5.2 & 590.8 & 481.4 & 1.23 & 7.3 & 215.6 & 36.3 & 30.6 \\
WDH5 & 8.0 & 664.7 & 553.9 & 1.20 & 5.7 & 209.7 & 36.5 & 31.3 \\
WDH6 & 8.0 & 672.4 & 567.5 & 1.19 & 5.7 & 212.4 & 42.6 & 35.7 \\
\hline
\end{tabular}

${ }^{a} \mathrm{R}_{\mathrm{m}}$ : measured tensile strength of reinforcement steel (mean value)

${ }^{\mathrm{b}} \mathrm{R}_{\mathrm{p} 0.2}$ : measured yield strength of reinforcement steel (mean value)

${ }^{c} \mathrm{R}_{\mathrm{m}} / \mathrm{R}_{\mathrm{p} 0.2}$ : strain hardening ratio of reinforcement steel (mean value)

${ }^{\mathrm{d}} \mathrm{A}_{\mathrm{gg}}$ : measured total elongation at peak force of reinforcement steel (mean value)

${ }^{e} \mathrm{E}_{\mathrm{s}}$ : measured modulus of elasticity of reinforcement steel (mean value)

${ }^{t} \mathrm{f}_{\mathrm{c}}$ : compression strength of concrete measured on cylinder (mean value)

${ }^{g} \mathrm{E}_{\mathrm{s}}$ : measured modulus of elasticity of concrete (mean value)

WDH1 and WDH2 as well as WDH3 and WDH4 were identical. This was done to make possible a comparison of the loading sequence on the wall behavior. The design was essentially achieved using the capacity design method [8]. Only WDH5 was designed conventionally according to the Swiss Building Code [9]. It was not possible to test walls with high ductility because of limitations of the test set-up. Therefore, capacity design for the ductility class DC"M" ("limited ductility") with a displacement ductility of $\mu_{\Delta}=3$ was used. The use of capacity design with this ductility class has almost no effects except on the spacing of the stabilising reinforcement in the plastic region (no requirement for concrete confinement, for instance). The reinforcement at the base of the walls WDH3 to WDH6 is shown in Fig. 2.

\section{2 Test set-up}

The test set-up is shown in Fig. 3. The earthquake simulator consists of the shake table, the jack moving it and the electronic command. The wall footing was rigidly connected to the shake table which operates in one horizontal direction and may move up to $125 \mathrm{~mm}$ in each direction [7]. The test set-up simulates the main features of the 3-storey prototype building shown in Fig. 1 (left). Rolling steel carts loaded with $12 \mathrm{t}$ of steel bars constituted the three storey masses. They 
WDH3 and WDH4

\section{Cross section}
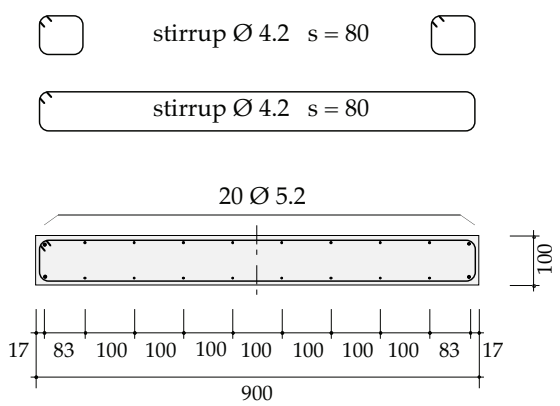

\section{Elevation}

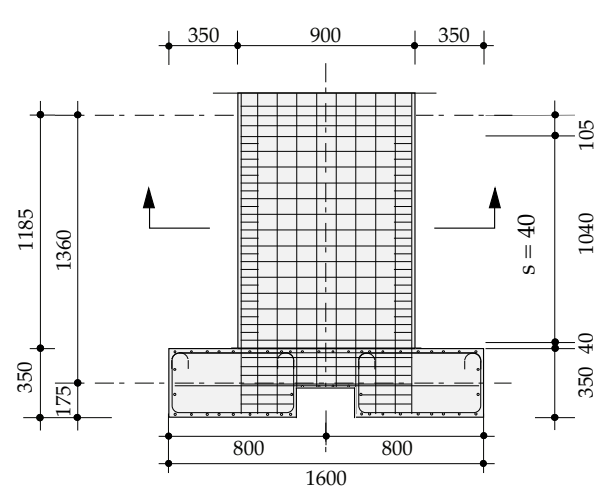

WDH5 and WDH6
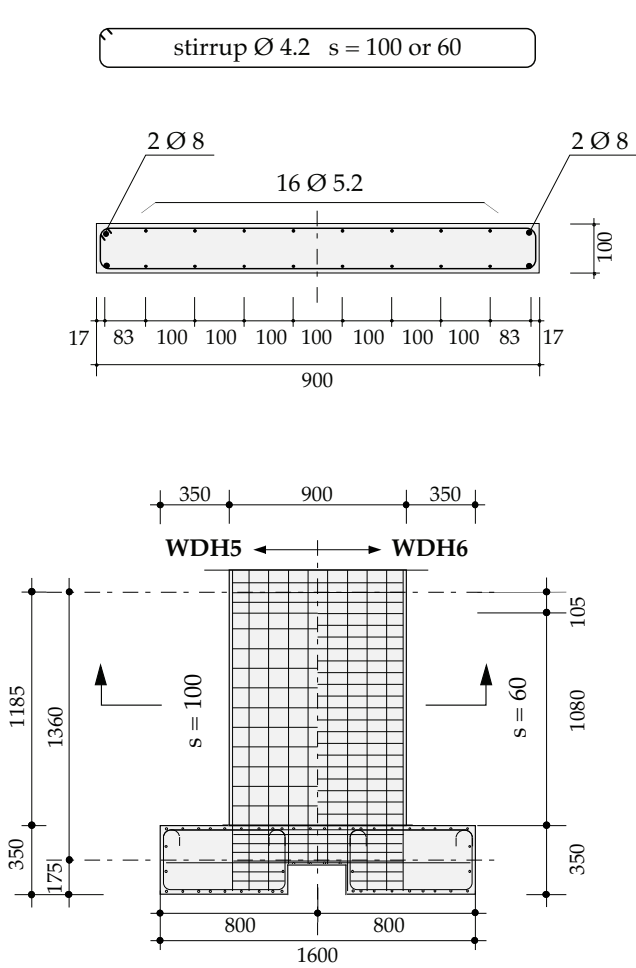

Fig. 2. Reinforcement at the wall's base for the test walls WDH3 to WDH6 (dimensions in mm).

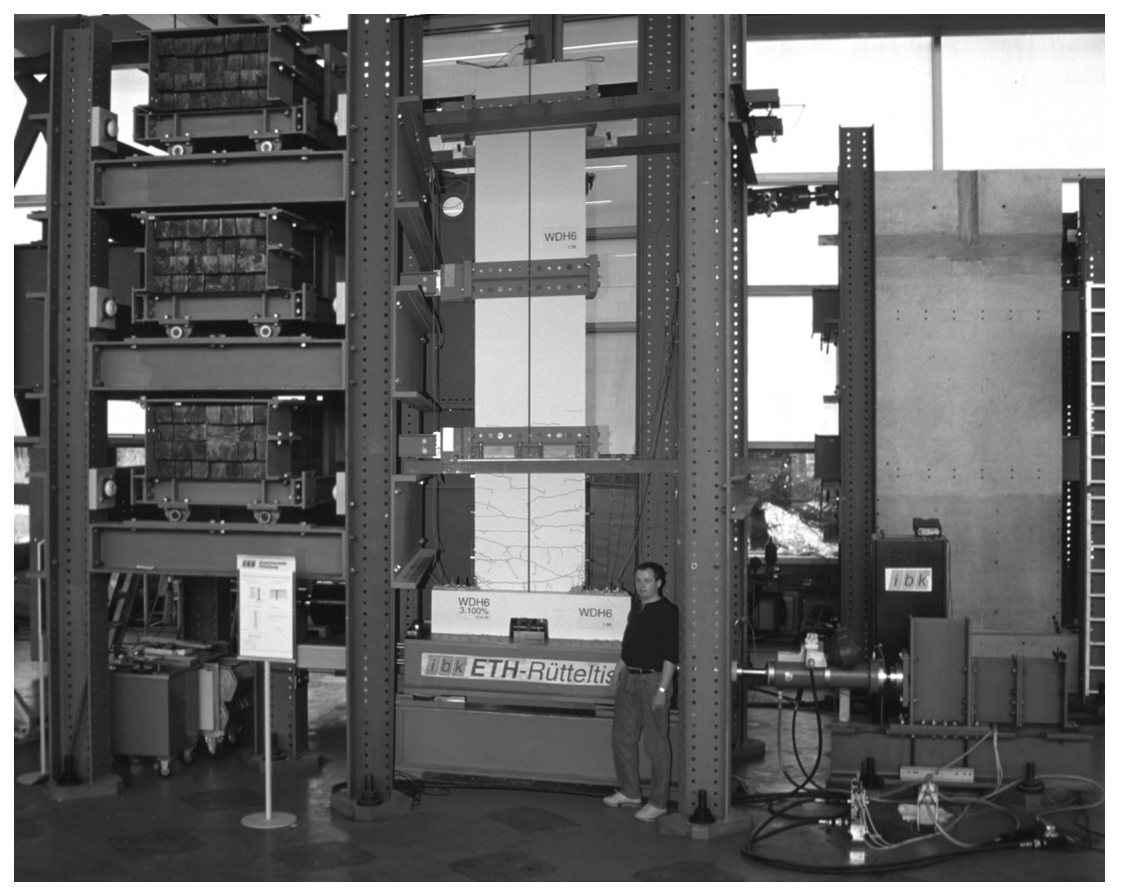

Fig. 3. Test set-up with wall WDH6 [1]. 
were placed on rails, mounted to the separate structure, on which they could move freely except for slight friction damping due to their rolling. The external post-tensioning bars simulating the axial gravity load force at the wall base (plastic region) were attached to the shake table and at the top of the wall. The resulting time-histories of dynamic bending moments and shear forces together with the axial force simulate well the solicitations in the wall during a real earthquake.

\section{3 Synthetic earthquakes}

Two synthetic spectrum-compatible earthquakes were used for the tests in order to facilitate the comparison of the results with the codes' assumptions. The synthetic earthquakes were generated using a classical stationary simulation [10]. Fig. 4 and 5 show the two synthetic earthquakes. The acceleration time-history (left) and the related acceleration response spectra (right) are plotted.
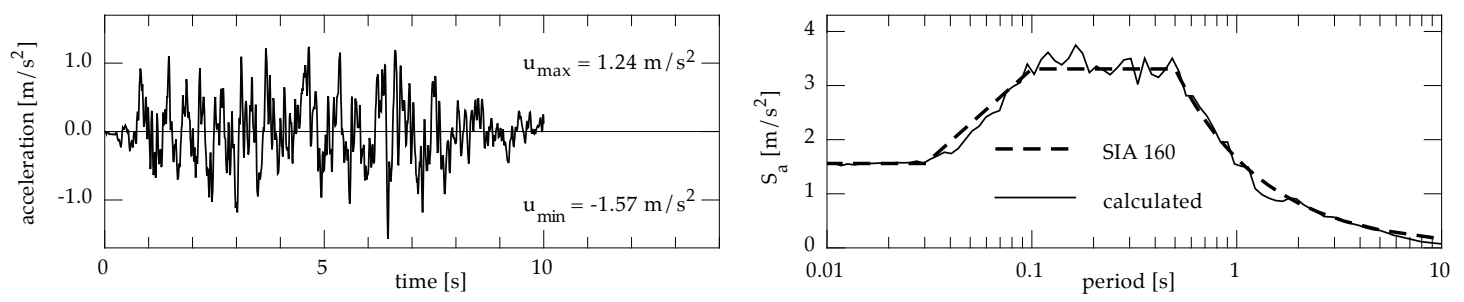

Fig. 4. Synthetic earthquake for medium-stiff soils, compatible with SIA 160's design spectrum.
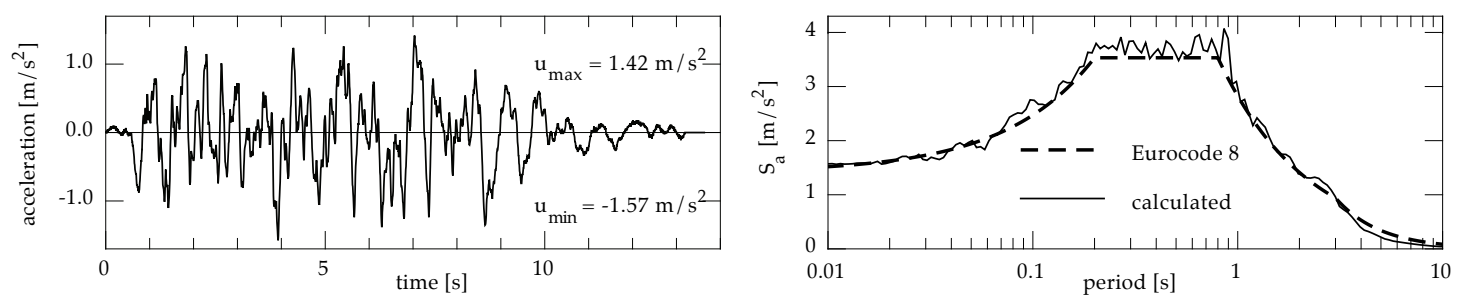

Fig. 5. Synthetic earthquake for soft soils, compatible with SIA 160's design spectrum (adapted from Eurocode 8).

Both synthetic earthquakes simulate a design earthquake valid for the most severe seismic zone (Zone 3b) of the Swiss Earthquake Code regulations SIA 160 [11] for a peak ground acceleration of $1.6 \mathrm{~m} / \mathrm{s}^{2}$, however for different soil conditions. Fig. 4 shows the ground motion for medium-stiff soils. The corner frequencies of $2 \mathrm{~Hz}$ and $10 \mathrm{~Hz}$ define the plateau with a constant spectral acceleration of $3.4 \mathrm{~m} / \mathrm{s}^{2}$. The earthquake lasts 10 seconds. Fig. 5 shows the ground motion for soft soils. Since Swiss earthquake code regulations did not include soft soil conditions, the shape of the design spectra was adapted from Eurocode 8 [12]. The corner frequencies of $1.25 \mathrm{~Hz}$ and $5 \mathrm{~Hz}$ define the plateau with a constant spectral acceleration of 3.6 $\mathrm{m} / \mathrm{s}^{2}$. This second earthquake lasts approximately 14 seconds.

Each wall was subjected to several tests. The sequence of the test is indicated in Tables 6 and 7 in sections 3 and 4 . An $80 \%$ earthquake means that the accelerations of the test excitation reached $80 \%$ of the accelerations of the reference synthetic earthquakes shown in Fig. 4 (with "m" for medium-stiff soils) and Fig. 5 (with "s" for soft soils).

\section{4 Results}

Only essential results are presented in this section. The entire test result set can be found in [1]. 

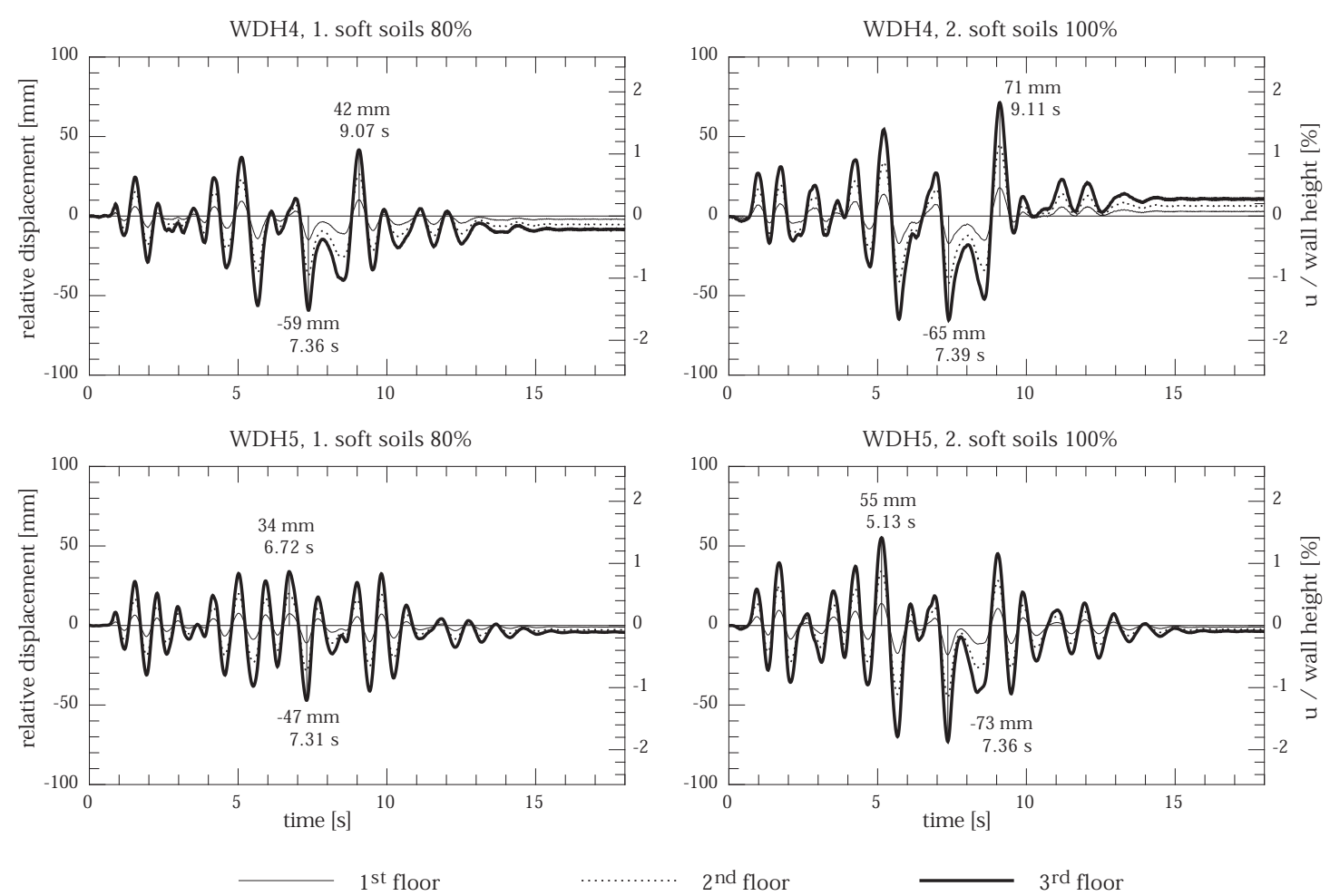

Fig. 6. Time-histories of the relative displacements of the walls WDH4 and WDH5 in the first two tests [1].
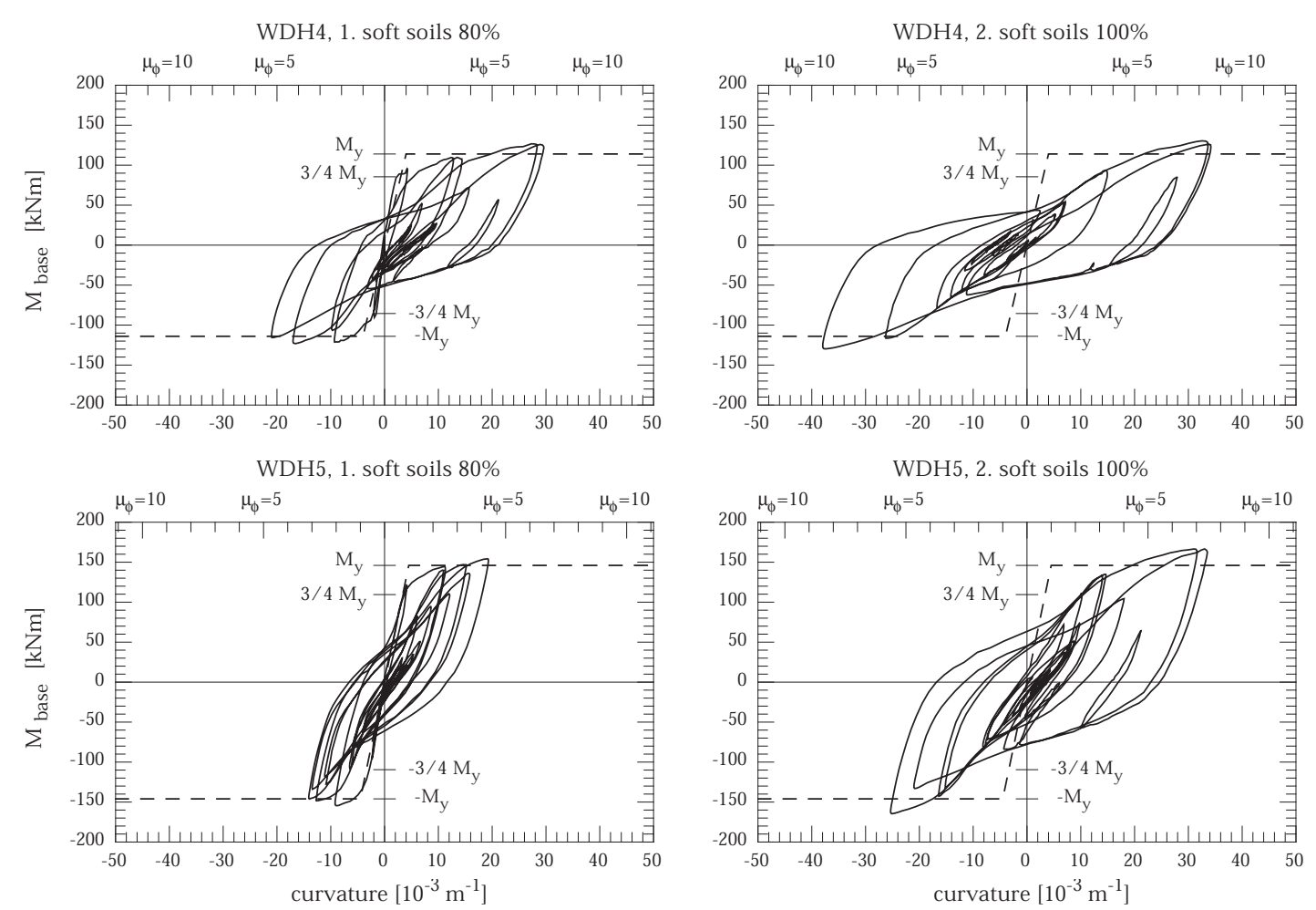

Fig. 7. Bending moment curvature hysteretic loops in the plastic region at the base of the walls WDH4 and WDH5 in the first two tests [1].

The walls WDH3 to WDH6 have reached peak relative displacements of more than $70 \mathrm{~mm}$ in the $3^{\text {rd }}$ floor without failure with a $100 \%$ earthquake. These peak values correspond to an 
average storey drift of about $1.8 \%$ (see Table 6). Fig. 6 shows the relative displacement timehistories measured in the first two tests of the walls WDH4 and WDH5. The peak values reached in the $3^{\text {rd }}$ floor and the related times are indicated.

The bending moment curvature hysteretic loops in the plastic region at the wall base are very stable. They presented practically no decrease in the resistance and, as expected with slender structural walls, no excessive pinching [13]. Fig. 7 shows the bending moment curvature hysteretic loops at the wall base in the first two tests of the walls WDH4 and WDH5. Curvature ductilities as high as $\mu_{\phi}=9.5$ were reached at the wall base before failure.

\section{Experimental determination of yield displacement}

\section{1 Definition}

Based on a bilinear, ideal elastoplastic force displacement relationship, the yield displacement is defined as the displacement of the wall top (upper wall end) at the onset of yielding. According to Fig. 8, the displacement ductility of a complete structural wall can be defined as the ratio of the total elastoplastic displacement of the wall top to the yield displacement $\left(\mu_{\Delta}=\mathrm{u}_{\text {tot }} / \mathrm{u}_{\mathrm{y}}\right)$.

However, as illustrated on Fig. 8, the measured force displacement relationship diverges notably from the idealised bilinear relationship because plastic deformations appear much before the flexural strength is reached. As a consequence the direct use of the above definition is not straightforward and additional assumptions and rules are needed to determine a nominal displacement at the onset of yielding.

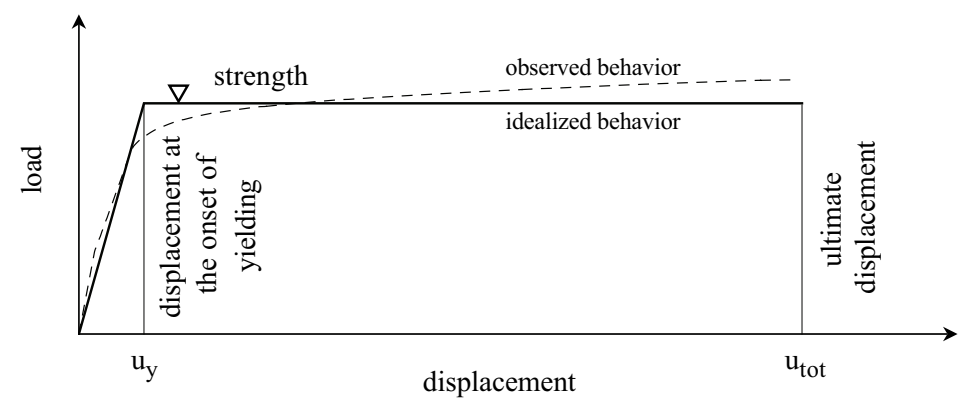

Fig. 8. Definition of displacement ductility $\left(\mu_{\Delta}=u_{\text {tot }} / u_{y}\right)[13]$.

\section{2 Determination of the yield curvature from test measurements}

The yield curvature $\phi_{\mathrm{y}}$ may be determined from test measurements, for example with the often used empirical $\alpha$-rule [13]. The parameter $\alpha$ is generally fixed to $\alpha=3 / 4$. As shown in Fig. 9 (left) for a monotonic loading the idealised bending moment curvature behavior is determined by two straight lines: the horizontal at flexural strength $\mathrm{M}_{\mathrm{y}}$ and the secant between origin and the measured curve at 3/4 $\mathrm{M}_{\mathrm{y}}$. The flexural strength $\mathrm{M}_{\mathrm{y}}$ is calculated under the assumption of an idealised elastoplastic reinforcement steel behavior. It corresponds to the flexural strength when reaching the nominal concrete ultimate strain $\left(\varepsilon_{\mathrm{cu}}=0.0035\right.$ see Fig. 9 to the right). The difference between $\mathrm{M}_{\mathrm{y}}$ and the measured flexural strength corresponds to the overstrength (effective material strength). When using this procedure with dynamic test results the mean of the determined values for both displacement directions should be considered. 

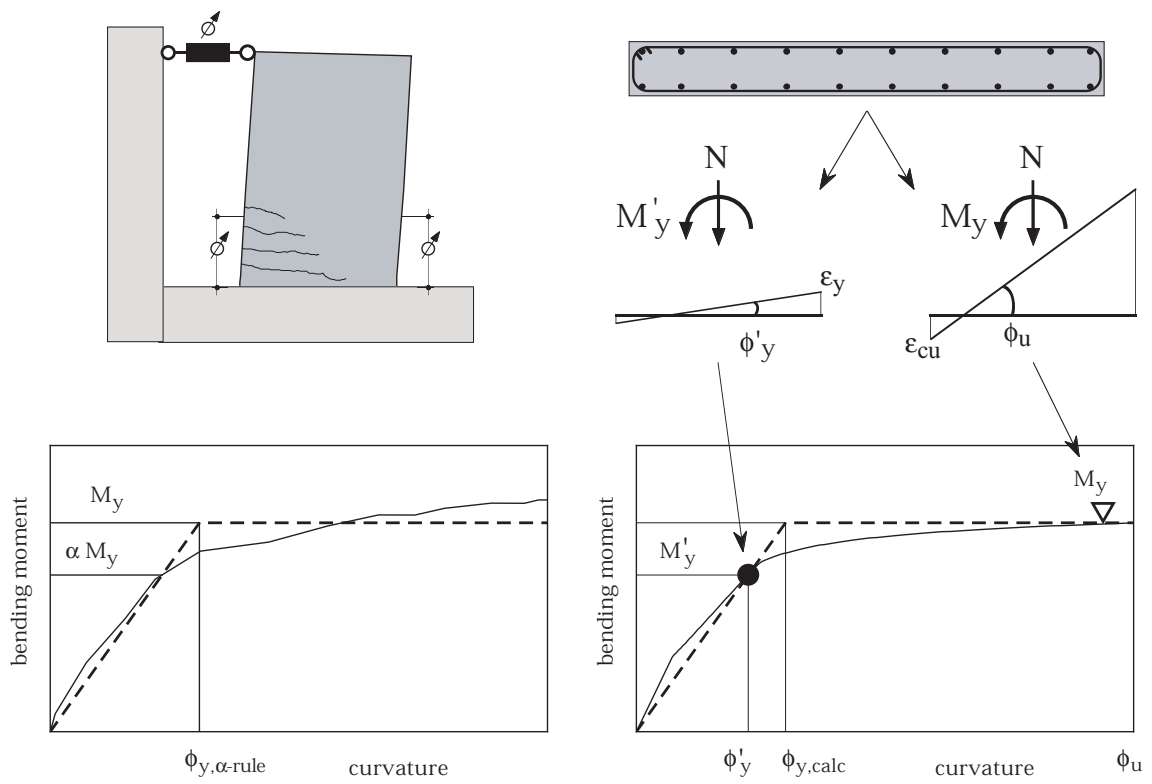

Fig. 9. Yield curvature: determination from measurements with the $\alpha$-rule (left) and calculation from wall cross section with idealised material and geometric behavior (right).

\section{3 Calculation of the yield curvature}

The yield curvature $\phi_{\mathrm{y}}$ may also be calculated. Based on a triangular distribution of the concrete stress and neglecting the participation of the stretched concrete, the curvature $\phi_{\mathrm{y}}^{\prime}$ and the flexural strength $\mathrm{M}_{\mathrm{y}}^{\prime}$ at the onset of yielding (peak steel strain equal to the steel yield strain $\varepsilon_{\mathrm{y}}$ ) may be calculated. As shown in Fig. 9 (right), the point at the onset of yielding $\left(\phi_{y}^{\prime} ; \mathrm{M}_{\mathrm{y}}^{\prime}\right)$ defines from the origin a straight line whose intersection with the horizontal line at the calculated flexural strength $\mathrm{M}_{\mathrm{y}}$ may be considered as the nominal yield curvature. The calculated yield curvatures for the walls WDH1 to WDH6 are summarized in the Table 3. The values (second last column) correspond well with the nominal yield curvatures determined according to the $\alpha=3 / 4$-rule (third last column) [3].

Table 3

Calculated yield curvature of the test walls [3]

\begin{tabular}{ccccccccc}
\hline Wall & $\begin{array}{c}1_{\mathrm{w}} \\
{[\mathrm{m}]}\end{array}$ & $\begin{array}{c}\phi_{\mathrm{y}}{ }^{\mathrm{a}} \\
{\left[\mathrm{km}^{-1}\right]}\end{array}$ & $\begin{array}{c}\mathrm{M}_{\mathrm{y}}{ }^{\mathrm{b}} \\
{[\mathrm{kNm}]}\end{array}$ & $\begin{array}{c}\mathrm{M}_{\mathrm{y}}{ }^{\mathrm{c}} \\
{[\mathrm{kNm}]}\end{array}$ & $\begin{array}{c}\varepsilon_{\mathrm{y}}{ }^{\mathrm{d}} \\
{[\%]}\end{array}$ & $\begin{array}{c}\phi_{\mathrm{y}, 3 / 4 \mathrm{rull}{ }^{\mathrm{e}}} \\
{\left[\mathrm{km}^{-1}\right]}\end{array}$ & $\begin{array}{c}\phi_{\mathrm{y}, \text { calc }}{ }^{\mathrm{f}} \\
{\left[\mathrm{km}^{-1}\right]}\end{array}$ & $\begin{array}{c}2 \varepsilon_{\mathrm{y}} / 1_{\mathrm{w}} \\
{\left[\mathrm{km}^{-1}\right]}\end{array}$ \\
\hline WDH1 & 1.00 & 3.04 & 114.2 & 157.5 & 0.242 & 4.0 & 4.2 & 4.8 \\
WDH2 & 1.00 & 3.02 & 114.9 & 158.0 & 0.242 & 4.0 & 4.2 & 4.8 \\
WDH3 & 0.90 & 3.09 & 81.7 & 113.2 & 0.220 & 4.0 & 4.3 & 4.9 \\
WDH4 & 0.90 & 3.16 & 82.1 & 114.3 & 0.223 & 4.0 & 4.4 & 5.0 \\
WDH5 & 0.90 & 3.75 & 117.4 & 144.9 & 0.264 & 4.5 & 4.6 & 5.9 \\
WDH6 & 0.90 & 3.75 & 120.2 & 147.7 & 0.267 & 4.5 & 4.6 & 5.9 \\
\hline
\end{tabular}

${ }^{a} \phi_{y}^{\prime}:$ curvature at the onset of yielding

${ }^{b} \mathrm{M}_{\mathrm{y}}$ : flexural strength at the onset of yielding

${ }^{\circ} \mathrm{M}_{\mathrm{y}}$ : flexural strength calculated with mean values of measured yield strength

${ }^{\mathrm{d}} \varepsilon_{\mathrm{y}}$ : yield strain of reinforcement steel $\left(\varepsilon_{\mathrm{y}}=\mathrm{R}_{\mathrm{p} 0.2} / \mathrm{E}\right)$

${ }^{\mathrm{e}} \phi_{\mathrm{y}, 3 / \text { rule }}$ : yield curvature determined with the $\alpha=3 / 4$-rule

${ }^{\mathrm{f}} \phi_{\mathrm{y}, \text { calc }}:$ nominal yield curvature $\phi_{\mathrm{y}}=\phi_{\mathrm{y}}^{\prime} \mathrm{M}_{\mathrm{y}} / \mathrm{M}_{\mathrm{y}}$ 
An approximation of the nominal yield curvature is given in the last column of Table 3 for comparison. Priestley and Kowalsky [14] have shown that the nominal yield curvature for a rectangular cantilever is barely influenced by the modification of the normal force, the reinforcement ratio and the distribution of the vertical reinforcement. For design purposes they have proposed a simple approximation as a function of the wall length and the steel yield strain: $2 \varepsilon_{\mathrm{y}} / 1_{\mathrm{w}}$. Comparison of the last two columns of Table 3 reveals that the approximation overestimates the nominal yield curvature by about $15 \%$ for the first four walls. The approximation is worse for the last two walls, however it must be remembered, that the relationship of Priestley and Kowalsky [14] was proposed for a yield strength $\left(\mathrm{R}_{\mathrm{P} 0.2}\right)$ less than $500 \mathrm{MPa}$ which is not the case for the reinforcement steel used in walls WDH5 and WDH6 (see Table 2). Instead of 2.0 the tests thus gave values of 1.75 for the walls WDH1 to WDH4 and 1.56 for WDH5 and WDH6.

\section{4 Calculation of the yield displacement}

Using the simple elastic beam theory without considering shear deformations, the yield displacement may be calculated from the yield curvature. A single-degree-of-freedom system (SDOF) is shown in Fig. 10 (left). The yield displacement $\left(\mathrm{u}_{\mathrm{y}}\right)$ may be calculated with the elastic bending moment curvature relationship $\left(\phi_{\mathrm{y}}=\mathrm{M}_{\mathrm{y}} / \mathrm{EI}\right)$ as follows:

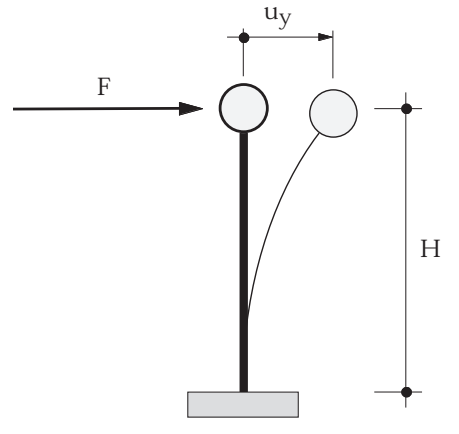

$\mathrm{M}_{\mathrm{base}}=\mathrm{F} \cdot \mathrm{H}$

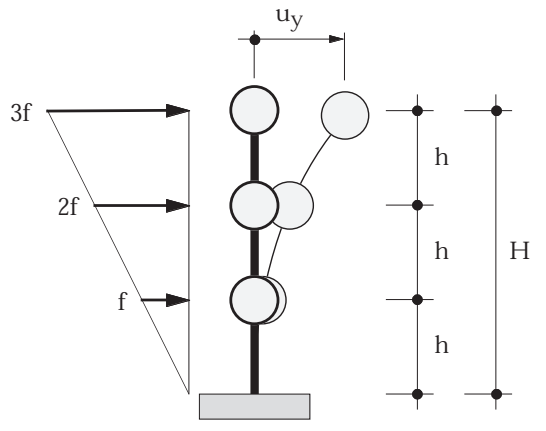

$M_{\text {base }}=14 \cdot f \cdot h$

Fig. 10. Top displacement calculation for a single-degree-of-freedom system (left) and for a three-degree-offreedom system with a triangular force distribution (right).

$$
\mathrm{u}_{\mathrm{y}}=\frac{\mathrm{F}_{\mathrm{y}} \cdot \mathrm{H}^{3}}{3 \cdot \mathrm{EI}}=\frac{\left(\mathrm{F}_{\mathrm{y}} \cdot \mathrm{H}\right) \cdot \mathrm{H}^{2}}{3 \cdot \mathrm{EI}}=\frac{\mathrm{M}_{\mathrm{y}} \cdot \mathrm{H}^{2}}{3 \cdot \mathrm{EI}}=\frac{\mathrm{M}_{\mathrm{y}}}{\mathrm{EI}} \cdot \frac{\mathrm{H}^{2}}{3}=\phi_{\mathrm{y}} \cdot \frac{\mathrm{H}^{2}}{3} \cong 0.33 \cdot \phi_{\mathrm{y}} \cdot \mathrm{H}^{2}
$$

For a multi-degree-of-freedom system (MDOF) a force distribution over its height must be assumed. A three-degree-of-freedom system with a triangular force distribution is shown in Fig. 10 (right). The yield displacement $\left(\mathrm{u}_{\mathrm{y}}\right)$ may also be calculated with the elastic bending moment curvature relationship $\left(\phi_{\mathrm{y}}=\mathrm{M}_{\mathrm{y}} / \mathrm{EI}\right)$ :

$$
\mathrm{u}_{\mathrm{y}}=\frac{113 \cdot \mathrm{f}_{\mathrm{y}} \cdot \mathrm{h}^{3}}{3 \cdot \mathrm{EI}}=\frac{113 \cdot \mathrm{M}_{\mathrm{y}} \cdot \mathrm{h}^{2}}{42 \cdot \mathrm{EI}}=\frac{113 \cdot \mathrm{M}_{\mathrm{y}} \cdot \mathrm{H}^{2}}{378 \cdot \mathrm{EI}}=\frac{113 \cdot \phi_{\mathrm{y}} \cdot \mathrm{H}^{2}}{378} \cong 0.30 \cdot \phi_{\mathrm{y}} \cdot \mathrm{H}^{2}
$$

The yield displacements calculated with Eq. (2) for the walls WDH1 to WDH6 are given in Table 4. From the calculated nominal yield curvatures (Table 3 second last column) a yield displacement of $\mathrm{u}_{\mathrm{y}}$ from 21 to $22 \mathrm{~mm}$ is adequate for the first four walls (Table 4 column 4 ). For the two last walls the value must be increased by about $10 \%$ up to $\mathrm{u}_{\mathrm{y}}=23 \mathrm{~mm}$. The yield displacement is slightly overestimated if it is calculated with the nominal yield curvature 
proposed by Priestley and Kowalsky [14] (Table 4 column 6). In contrast the yield displacement is slightly underestimated if it is calculated with the nominal yield curvature according to the $\alpha=3 / 4$-rule (Table 4 column 8 ).

\begin{tabular}{|c|c|c|c|c|c|c|c|c|}
\hline \multicolumn{9}{|c|}{ Calculated yield displacement of the test walls [3] } \\
\hline \multirow{3}{*}{ Wall } & 1 & 2 & 3 & 4 & 5 & 6 & 7 & 8 \\
\hline & $1_{\mathrm{w}}$ & $\varepsilon_{\mathrm{y}}$ & $\phi_{\mathrm{y}, \text { calc }}$ & $\mathrm{u}_{\mathrm{y}}$ & $2 \varepsilon_{\mathrm{y}} / 1_{\mathrm{w}}$ & $\mathrm{u}_{\mathrm{y}}$ & $\phi_{\mathrm{y}, 3 / 4 \mathrm{rule}}$ & $\mathrm{u}_{\mathrm{y}}$ \\
\hline & {$[\mathrm{m}]$} & [\%] & {$\left[\mathrm{km}^{-1}\right]$} & {$[\mathrm{mm}]$} & {$\left[\mathrm{km}^{-1}\right]$} & {$[\mathrm{mm}]$} & {$\left[\mathrm{km}^{-1}\right]$} & {$[\mathrm{mm}]$} \\
\hline WDH1 & 1.00 & 0.242 & 4.2 & 21.0 & 4.8 & 24.2 & 4.0 & 20.0 \\
\hline WDH2 & 1.00 & 0.242 & 4.2 & 21.0 & 4.8 & 24.2 & 4.0 & 20.0 \\
\hline WDH3 & 0.90 & 0.220 & 4.3 & 21.5 & 4.9 & 24.4 & 4.0 & 20.0 \\
\hline WDH4 & 0.90 & 0.223 & 4.4 & 22.0 & 5.0 & 24.8 & 4.0 & 20.0 \\
\hline WDH5 & 0.90 & 0.264 & 4.6 & 23.0 & 5.9 & 29.3 & 4.5 & 22.5 \\
\hline WDH6 & 0.90 & 0.267 & 4.6 & 23.0 & 5.9 & 29.7 & 4.5 & 22.5 \\
\hline
\end{tabular}

\section{5 Determination of the yield displacement from test measurements}

For the experimental determination of the yield displacement of a MDOF system, the empirical rules for the determination of the yield curvature cannot be used. Several modes of vibration are involved in the vibration of a MDOF system. This is also the case for plastic behavior particularly at the beginning of an earthquake with an uncracked wall. The force distribution over the wall height is strongly modified during the vibrations and consequently also the shape of the deflection curve. The relationship between the top deformation and the stress and strain at the wall base is no more direct. As a consequence, a top deformation at the onset of yielding at the wall base is difficult to determine from the test measurements. SDOF systems are not affected by this problem because the position of the single force is fixed.

It would be desirable to be able to extract the yield displacement directly from the test results. One may be tempted to use the $\alpha$-rule directly with the bending moment relative displacement relationship. Fig. 11 shows the related hysteretic loops for the two first tests of the wall WDH4. The bending moment at the upper side of the wall footing is plotted as a function of the relative displacement of the $3^{\text {rd }}$ floor. The plotted envelopes (broken lines) are drawn with the calculated yield displacement of the last column of Table 4 . The direct use of the $\alpha=3 / 4$-rule would in the first test lead to a value of the yield displacement smaller than half of the calculated one. The first test was performed with a still uncraked wall. The initial cycles show a large stiffness, they are
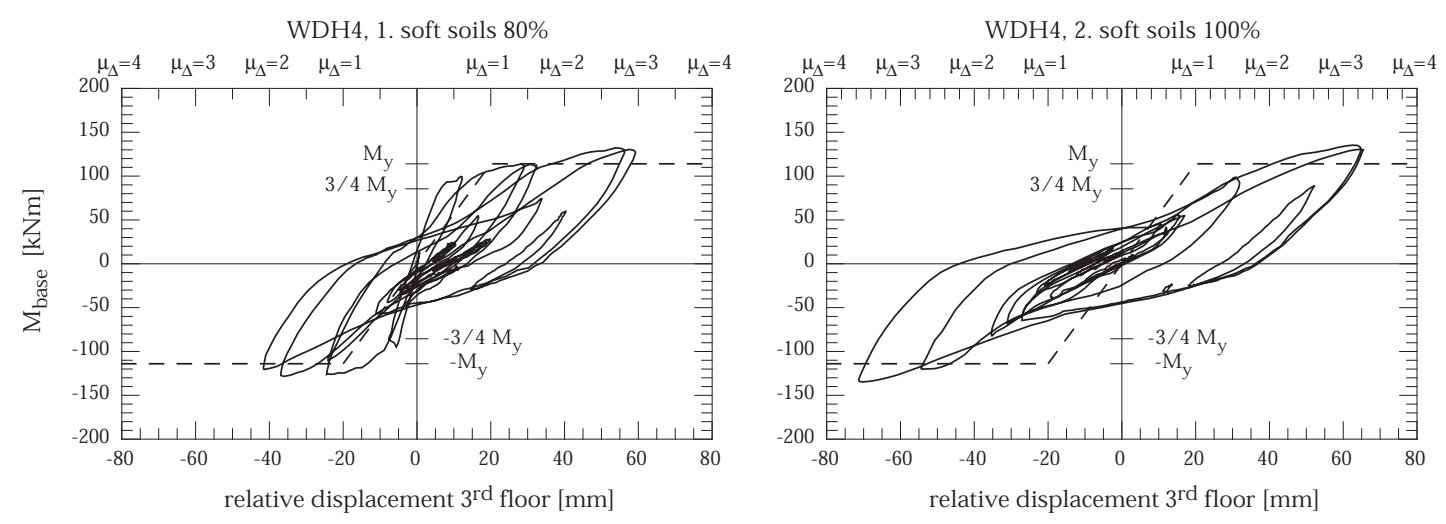

Fig. 11. Bending moment relative displacement relationships of the first two tests of the wall WDH4. The yield displacement cannot be extracted from the hysteretic loops with an $\alpha$-rule. The envelopes (broken lines) are drawn with the calculated yield displacements of the last column of Table 4 [3]. 
not decisive in the estimation of the seismic behavior of the wall. The yield displacement does not clearly appear in the hysteretic loops of the second test which is an already damaged wall.

Another representation of the test results must be found. The relative displacement must be plotted as a function of a well chosen measured value in order to highlight a pronounced modification in the wall behavior. Fig. 12 shows the relative displacement measured at the $3^{\text {rd }}$ floor as a function of the vertical displacement of a point on the wall base (Fig. 13) for the first two tests of wall WDH5. To measure the vertical displacement of a point on the wall base, the displacement transducer was fixed at the bottom on the upper side of the wall footing and at the top on the surface of the wall. The results from both wall sides are plotted in the same graph. The vertical displacements are positive for an elongation. In Fig. 12, the positive displacements show tension and the negative displacements compression on wall side. In the tensile region a clear break in the loops appears at a relative displacement of approximately $25 \mathrm{~mm}$. The break is identified by the slope variation of the tangent (dotted lines). The relative displacement at the intersection of both tangents marks a limit displacement where the wall behavior is modified. The locations of the breaks vary slightly with the considered wall sides and tests. As the yield displacement may be considered as a cross-sectional property, mean values must be considered.
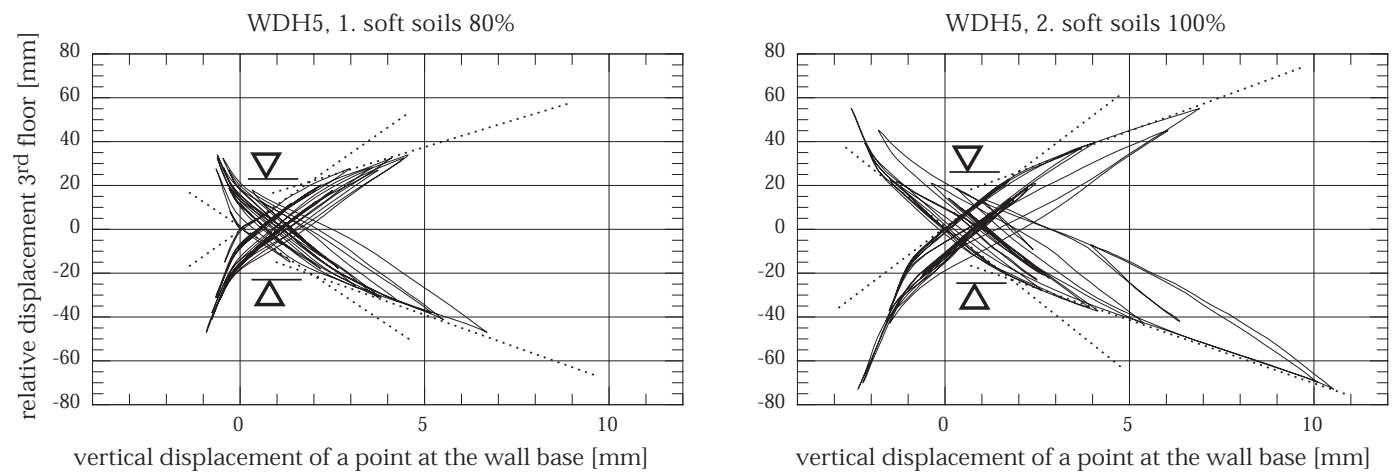

Fig. 12. Relative displacements in the $3^{\text {rd }}$ floor as a function of the vertical displacement of a point on the wall base in the first two tests of wall WDH5. The slope modification of the tangent (dotted lines) marks a pronounced break in the loops. This break shows the modification of the wall behavior [3].

Fig. 13 shows schematically the modification of the wall behavior from the small (left) to the large displacements (right). For small vertical displacements of the considered point $\mathrm{P}$ the wall exhibits approximately an elastic behavior. Each part of the wall contributes to the wall top relative displacement $\left(\mathrm{u}_{\mathrm{v}}\right)$. In contrast the deformations are concentrated at the wall base when the behavior of the wall becomes plastic. Only the lowest part of the wall contributes to the additional top displacement $\left(\mathrm{u}_{\mathrm{p}}\right)$. In the plastic state, the lowest part of the wall alone causes the corresponding top displacement and compared to the elastic state it must undergo proportionally more deformation to cause the same top displacement. The break in Fig. 12 highlights the stiffness variation. This method does not enable the determination of the yield displacement with a great precision but it has a key advantage: the located variation of the wall behavior is precisely what is desired to determine the displacement ductility. Surprisingly, the method can also be used with a wall already damaged (Fig. 12, right), which is not the case for the determination of the yield curvature with the $\alpha$-rule (see Fig. 7, right).

Fig. 12 shows that the breaks lie at higher values in the second tests. This tendency can be explained by the wall damage and the Bauschinger effect [15], [16]. Cyclic deformations up to yielding (in tension as well as in compression) lead to a decrease in the modulus of elasticity of the reinforcement steel. As a consequence of this decrease in stiffness, the modification of the wall behavior appears for a larger relative displacement.

The comparison in Table 5 of the determined values $\left(21 \mathrm{~mm}<\mathrm{u}_{\mathrm{y}, \text { test }}<25 \mathrm{~mm}\right)$ with the calculated yield displacements $\left(21 \mathrm{~mm}<\mathrm{u}_{\mathrm{y}}, \phi_{\text {calc }}<23 \mathrm{~mm}\right.$ and $\left.20 \mathrm{~mm}<\mathrm{u}_{\mathrm{y},} \phi_{3 / 4 \text { rule }}<22.5 \mathrm{~mm}\right)$ 

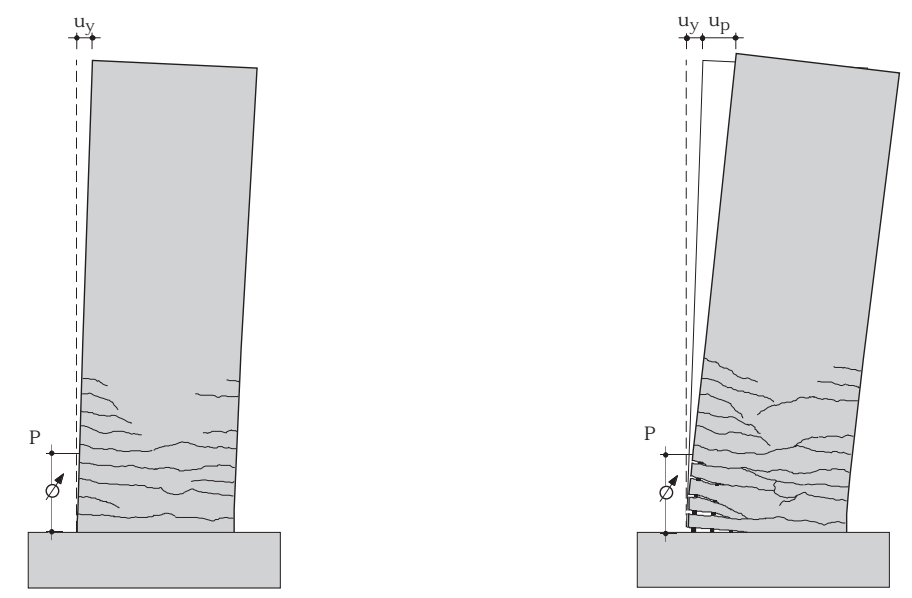

Fig. 13. Schematic representation of the modification of the wall behavior. By small vertical displacements of the point $\mathrm{P}$ (left) each part of the wall contributes to the top displacement $\left(\mathrm{u}_{\mathrm{y}}\right)$. The additional displacement $\left(\mathrm{u}_{\mathrm{p}}\right)$ is caused by the lowest part alone (right) [3].

shows a satisfactory correspondence. The displacement ductility reached during the tests may therefore be computed with a nominal value $\left(\mathrm{u}_{\mathrm{y}, \text { nom }}\right)$ corresponding to the calculated ones $\left(\mathrm{u}_{\mathrm{y}}, \phi_{\text {calc }}\right)$ but assumed constant for the same walls $\left(\mathrm{u}_{\mathrm{y}, \mathrm{nom}}=21 \mathrm{~mm}\right.$ for WDH1 to WDH4 and $\mathrm{u}_{\mathrm{y}, \text { nom }}=23 \mathrm{~mm}$ for WDH5 and WDH6).

Table 5

Summary of the yield displacement of the test walls

\begin{tabular}{ccccccc}
\hline Wall & $\begin{array}{c}\mathrm{1}_{\mathrm{w}} \\
{[\mathrm{m}]}\end{array}$ & $\begin{array}{c}\mathrm{u}_{\mathrm{y}, \text { Priestley }}{ }^{\mathrm{a}} \\
{[\mathrm{mm}]}\end{array}$ & $\begin{array}{c}\mathrm{u}_{\mathrm{y}, \phi_{\text {calc }}{ }^{\mathrm{b}}}^{[\mathrm{mm}]} \\
{[\mathrm{mm}}\end{array}$ & $\begin{array}{c}\mathrm{u}_{\mathrm{y},} \phi_{3 / \text { rulle }}{ }^{\mathrm{c}} \\
{[\mathrm{mm}]}\end{array}$ & $\begin{array}{c}\mathrm{u}_{\mathrm{y}, \text { test }}{ }^{\mathrm{d}} \\
{[\mathrm{mm}]}\end{array}$ & $\begin{array}{c}\mathrm{u}_{\mathrm{y}, \text { nom }}{ }^{\mathrm{e}} \\
{[\mathrm{mm}]}\end{array}$ \\
\hline WDH1 & 1.00 & 24.2 & 21.0 & 20.0 & 21.0 & 21.0 \\
WDH2 & 1.00 & 24.2 & 21.0 & 20.0 & 23.0 & 21.0 \\
WDH3 & 0.90 & 24.4 & 21.5 & 20.0 & 23.0 & 21.0 \\
WDH4 & 0.90 & 24.8 & 22.0 & 20.0 & 23.0 & 21.0 \\
WDH5 & 0.90 & 29.3 & 23.0 & 22.5 & 25.0 & 23.0 \\
WDH6 & 0.90 & 29.7 & 23.0 & 22.5 & 25.0 & 23.0 \\
\hline
\end{tabular}

${ }^{a} \mathrm{u}_{\mathrm{y}, \text { Priestley }}$ : calculated with the yield curvature proposed by priestley and Kowalsky [1998] (column 6 of Table 4)

${ }^{b} u_{y} \phi_{\text {calc }}:$ calculated with the calculated yield curvature (column 4 of Table 4)

${ }^{c} u_{y}, \phi_{3 / 4 r u l e}:$ calculated with the yield curvature determined with the $\alpha=3 / 4$ rule (column 8 of Table 4 )

${ }^{\mathrm{d}} \mathrm{u}_{\mathrm{y}, \text { test: }}$ : obtained with the adequate representation of the test results

${ }^{e} \mathrm{u}_{\mathrm{y}, \mathrm{nom}}$ : nominal, adopted value for the determination of the displacement ductility

\section{6 Displacement ductilities reached during the tests}

The displacement ductilities reached during the tests $\left(\mu_{\Delta}\right)$ summarized in Table 6 are the ratio of the peak relative displacements measured in the $3^{\text {rd }}$ floor to the yield displacement $\left(\mathrm{u}_{3}\right.$ floor $\left./ \mathrm{u}_{\mathrm{y}}\right)$. The average storey drift $\left(\delta_{\mathrm{m}}\right)$ are also provided in Table 6 in order to enable a direct comparison with $\mu_{\Delta}$. Note that since the walls behavior was controlled by the fundamental mode of vibration, differences to critical storey drift are small.

\section{7 Discussion of the results}

In this study, the wall design was achieved with the use of a strength reduction factor $(\mathrm{K})$ for the "elastic" seismic forces. The strength reduction factor is the ratio of the strength required for 


\begin{tabular}{|c|c|c|c|c|c|c|}
\hline \multicolumn{7}{|c|}{ Displacement ductilities reached during the tests } \\
\hline \multirow[t]{2}{*}{ Wall } & \multirow[t]{2}{*}{ test } & \multirow[t]{2}{*}{ earthquake $^{a}$} & \multirow{2}{*}{$\begin{array}{l}\mathrm{u}_{3 \text { floor }} \\
{[\mathrm{mm}]}\end{array}$} & \multirow{2}{*}{$\begin{array}{l}\delta_{\mathrm{m}}{ }^{\mathrm{b}} \\
{[\%]}\end{array}$} & \multirow{2}{*}{$\begin{array}{l}\mathrm{u}_{\mathrm{y}, \mathrm{nom}} \\
{[\mathrm{mm}]}\end{array}$} & \multirow{2}{*}{$\begin{array}{l}\mu_{\Delta} \\
{[-]}\end{array}$} \\
\hline & & & & & & \\
\hline \multirow[t]{10}{*}{ WDH1 } & 1 & $\mathrm{~m} 20 \%$ & 8.0 & 0.20 & \multirow[t]{10}{*}{21} & 0.4 \\
\hline & 2 & $\mathrm{~m} 40 \%$ & 19.2 & 0.49 & & 0.9 \\
\hline & 3 & $\mathrm{~m} 70 \%$ & 27.9 & 0.71 & & 1.3 \\
\hline & 4 & $\mathrm{~m} 100 \%$ & 32.8 & 0.84 & & 1.6 \\
\hline & 5 & $\mathrm{~m} 100 \%$ & 32.8 & 0.84 & & 1.6 \\
\hline & 7 & $\mathrm{~m} 100 \%$ & 31.5 & 0.81 & & 1.5 \\
\hline & 8 & $\mathrm{~m} 100 \%$ & 31.9 & 0.82 & & 1.5 \\
\hline & 9 & m $120 \%$ & 36.4 & 0.93 & & 1.7 \\
\hline & 10 & s $20 \%$ & 14.8 & 0.38 & & 0.7 \\
\hline & 11 & s $100 \%$ & 43.7 & 1.12 & & 2.1 \\
\hline WDH2 & 1 & s $100 \%$ & 49.8 & 1.28 & 21 & 2.4 \\
\hline WDH3 & 1 & s $100 \%$ & 71.8 & 1.84 & 21 & 3.4 \\
\hline \multirow[t]{2}{*}{ WDH4 } & 1 & s $80 \%$ & 59.2 & 1.52 & \multirow[t]{2}{*}{21} & 2.8 \\
\hline & 2 & s $100 \%$ & 71.3 & 1.83 & & 3.4 \\
\hline \multirow[t]{2}{*}{ WDH5 } & 1 & s $80 \%$ & 47.0 & 1.20 & \multirow[t]{2}{*}{23} & 2.0 \\
\hline & 2 & s $100 \%$ & 73.0 & 1.87 & & 3.2 \\
\hline \multirow[t]{2}{*}{ WDH6 } & 1 & s $80 \%$ & 47.6 & 1.22 & \multirow[t]{2}{*}{23} & 2.1 \\
\hline & 2 & s $100 \%$ & 72.3 & 1.85 & & 3.1 \\
\hline
\end{tabular}

elastic behavior to the strength required for inelastic behavior. The walls WDH1 and WDH2 were designed with $\mathrm{K}=2.5$ for $100 \%$ earthquake for medium-stiff soils. WDH3 and WDH4 were designed with $\mathrm{K}=3.6$ for $100 \%$ earthquake for soft soils. WDH5 and WDH6 were designed with $\mathrm{K}=2.0$ for $80 \%$ earthquake for soft soils [1].

During the last test, WDH1 reached a displacement ductility of $\mu_{\Delta}=2.1$ before failure with $100 \%$ earthquake for soft soils. WDH 2 reached a displacement ductility of $\mu_{\Delta}=2.4$ with $100 \%$ earthquake for soft soils. These small values for WDH1 and WDH2 should be related to the poor ductility properties (limited strain hardening ratio) of the reinforcing steel (see Table 2). WDH3 and WDH4 reached displacement ductilities of $\mu_{\Delta}=3.4$ with $100 \%$ earthquake for soft soils. During the first tests with $80 \%$ earthquakes for soft soils WDH5 and WDH6 indeed reached a displacement ductility of $\mu_{\Delta}=2$.

The test results coincide with the design assumptions. According to the equal displacement rule, the value of displacement ductility should be equal to the strength reduction factor. The displacement ductilities reached are slightly smaller than the values of the strength reduction factors used. A difference between the values of $K$ used for the design and the values of $\mu_{\Delta}$ computed from the tests results must be found in the inherent safety margin of the static equivalent force method as the method uses the total mass instead of the modal mass for the determination of the static equivalent force.

The wall WDH1 reached a displacement ductility of only $\mu_{\Delta}=1.6$ with $100 \%$ earthquake for medium-stiff soils. This is due to the decrease in the fundamental frequency resulting from cracking and plastic deformations caused by the numerous tests with mostly weak earthquakes. The fundamental frequency fell well into the decreasing region of the response spectrum below the corner frequency of $2 \mathrm{~Hz}$ (see Fig. 4). As a consequence, the earthquake was no more able to induce large wall force. 


\section{Energy content}

The energy is calculated by integrating the different forces of the equation of motion with respect to the relative displacement [17], [3]. The integration is replaced by the sum of the energy increments $\Sigma \Delta \mathrm{E}_{\mathrm{i}}$ in order to compute the energy numerically. The energy increment $\Delta \mathrm{E}_{\mathrm{i}}$ is the product of a force $\mathrm{F}_{\mathrm{i}}$ with the related relative displacement increment $\Delta \mathrm{u}_{\mathrm{i}}$. The relative displacement increment may be determined through the approximation of its derivative with respect to time (relative velocity) with finite differences [17].

The absolute displacements were measured during the tests at each story and at the shake table, enabling a simple calculation of the relative displacements and velocities. The storey forces and the force in the jack acting on the shake table were also measured. The main objective of this section is to determine the energy dissipated by plastic deformations (hysteretic energy) using measured data.

According to Eq. (3), the total input energy $\left(\mathrm{E}_{\text {tot }}\right)$ is the sum of friction energy $\left(\mathrm{E}_{\text {frict }}\right)$, kinetic energy $\left(\mathrm{E}_{\text {kin }}\right)$, strain energy $\left(\mathrm{E}_{\text {elast }}\right)$, viscous damping energy $\left(\mathrm{E}_{\mathrm{D}}\right)$ and hysteretic energy $\left(\mathrm{E}_{\text {hyst }}\right)$ :

$$
E_{\text {tot }}=\left|E_{\text {frict }}\right|+E_{\text {kin }}+E_{\text {elast }}+E_{D}+E_{\text {hyst }}
$$

In the following the different energy parts and their calculations are described.

\section{1 Total input energy $E_{\text {tot }}$}

The total input energy $E_{\text {tot }}$ is first determined. It is calculated according to Eq. (4) with the measured jack forces $\left(\mathrm{F}_{\mathrm{g}}\right)$ and the shake table displacements $\left(\mathrm{u}_{\mathrm{g}}\right)$.

$$
\mathrm{E}_{\mathrm{tot}}=\sum \Delta \mathrm{E}_{\mathrm{tot}, \mathrm{i}}=\sum \mathrm{F}_{\mathrm{g}, \mathrm{i}} \cdot \Delta \mathrm{u}_{\mathrm{g}, \mathrm{i}}=\sum \mathrm{F}_{\mathrm{g}, \mathrm{i}} \cdot \frac{\mathrm{u}_{\mathrm{g}, \mathrm{i}+1}-\mathrm{u}_{\mathrm{g}, \mathrm{i}-1}}{2}
$$

\section{2 Friction energy $E_{\text {frict }}$}

A portion of energy is dissipated by friction, which particularly appears in the rolling of the moveable storey masses, in the pinned steel struts connecting the masses to the wall and in the shake table bearing. Relatively only a small amount of energy is dissipated by friction in the pinned struts and in the shake table. As a consequence only the energy dissipated by the rolling of the moveable masses is considered. It is called friction energy in the following. The friction energy $E_{\text {frict }}$ is calculated with a constant friction force, which corresponds to a fraction $\mu$ of the storey mass. On account of the special test set-up (see Fig. 1 and 3), $\mathrm{E}_{\text {frict }}$ is calculated with the measured absolute displacements. The friction force $\mu \mathrm{Mg}$ always acts in the opposite direction of the absolute displacement. As a consequence, the friction energy will always be negative, however the absolute value of $\mathrm{E}_{\text {frict }}$ is used in the following.

\section{3 Kinetic energy $E_{k i n}$}

At each point in time, a part of the total energy consists of kinetic energy. The kinetic energy $\mathrm{E}_{\text {kin }}$ is calculated from the absolute velocities [3] as follows:

$$
\mathrm{E}_{\mathrm{kin}}(\mathrm{t}=\mathrm{i} \cdot \Delta \mathrm{t})=\frac{1}{2} \cdot \mathrm{M}_{\text {tot }} \cdot \dot{\mathrm{u}}_{\mathrm{a}, \mathrm{i}}^{2}
$$


Where $\mathrm{M}_{\text {tot }}$ is the total moving mass. $\mathrm{M}_{\text {tot }}=12.6 \mathrm{t}$ [1] for each storey. The total kinetic energy is the sum of the parts in each storey. The kinetic energy is, on account of the square of the velocity in Eq. (5), always positive. It does not consist of energy increments which must be summed, but it describes the energy stored in the masses. This may then be converted into strain energy, dissipated or returned to the shake table (foundation).

\section{4 Strain energy $E_{\text {elast }}$}

At each point in time a part of the total energy consists of recoverable strain energy. This energy $\mathrm{E}_{\text {elast }}$ is not determined here.

\section{5 Viscous damping energy $E_{D}$}

In order to consider all further unavoidable energy dissipation (particularly material damping in the walls) but not the hysteretic energy (see below), some viscous damping is globally introduced. This energy may be calculated as follows:

$$
\mathrm{E}_{\mathrm{D}}=\mathrm{c} \cdot \sum \dot{\mathrm{u}}_{\mathrm{i}}^{2} \cdot \Delta \mathrm{t}
$$

This energy is calculated with a damping constant of $\mathrm{c}=3500 \mathrm{Ns} / \mathrm{m}$, which corresponds to a damping ratio of approximately $1.5 \%$ at a natural frequency of $1.5 \mathrm{~Hz}$.

\section{6 Hysteretic energy $E_{\text {hyst }}$}

A part of the energy is also dissipated by plastic deformations, particularly of the reinforcement steel. This energy is called the hysteretic energy and may be determined by different ways (see 4. 10).

\section{7 Energy time-histories}

The energy time-histories of the two first tests of wall WDH5 are plotted in Fig. 14. The figure
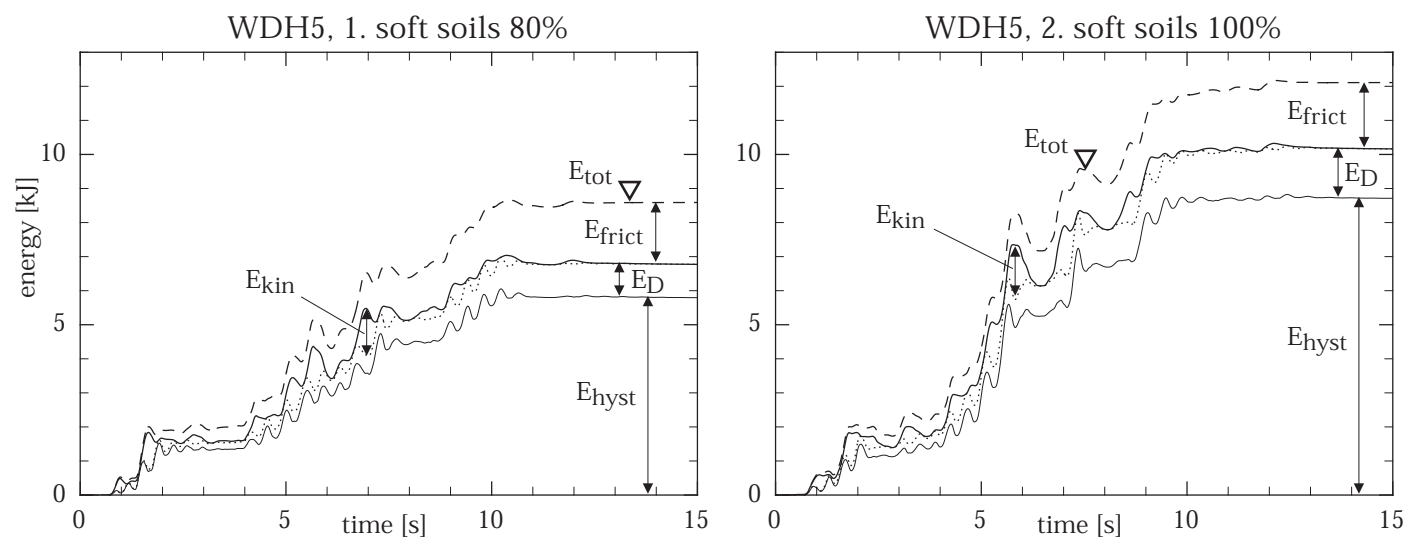

Fig. 14. WDH5, energy time-histories of the first two tests.

shows the total input energy $E_{\text {tot }}$ and also the energy time-history after subtraction of each of the 
energy portions mentioned above. The energy remaining at the end of the test after the free vibrations $(\mathrm{t}=\infty)$ corresponds to the energy dissipated by plastic deformations (hysteretic energy):

$$
\mathrm{E}_{\text {hyst }}(\mathrm{t}=\infty)=\mathrm{E}_{\text {tot }}(\mathrm{t}=\infty)-\mathrm{E}_{\text {frict }}(\mathrm{t}=\infty)-\mathrm{E}_{\mathrm{D}}(\mathrm{t}=\infty)
$$

These plots enable the description of the energy history of the tests. Relatively little energy is initially introduced to the system between approximately $\mathrm{t}=0.5 \mathrm{~s}$ and $1.5 \mathrm{~s}$. Afterwards very little energy is further introduced and the energy time-histories show a kind of plateau from approximately $1.5 \mathrm{~s}$ to $4.5 \mathrm{~s}$. The largest amount of energy was introduced after $4.5 \mathrm{~s}$. $\mathrm{E}_{\text {tot }}$ is sometimes seen to decrease since stored energy $\left(\mathrm{E}_{\text {kin }}\right.$ or $\left.\mathrm{E}_{\text {elast }}\right)$ was occasionally returned to the shake table (foundation).

\section{8 Energy with bending moments and rotations}

The hysteretic energy may also be calculated by integrating the bending moments $(\mathrm{M})$ with respect to the related segment rotations $(\theta)$ as follows:

$$
\mathrm{E}_{\text {hyst }}+\mathrm{E}_{\text {elast }}=\sum \mathrm{M}_{\mathrm{i}} \cdot \Delta \theta_{\mathrm{i}}
$$

The energy calculated with Eq. (8) contains the strain energy and is equal to the hysteretic energy at the end of the test, when the strain energy is zero.

The segment rotations are determined from the measured vertical displacements of some points in the wall base at both wall sides. These points define measuring lengths which divide the wall base in four segments (Fig. 15 right). The rotation and the bending moment are assumed constant through the segment height for determination of the energy. The energy is calculated as the product of the total rotation and the bending moment in the middle. The energy in each segment could thus be determined showing the distribution of the dissipated energy in the wall base. The energy for each of the four segments of the wall base are then summed.

\section{9 Input energy with storey forces and relative displacements}

The total energy may also be calculated in a different manner, Eq. (8) must then be transformed as follows:

$$
\mathrm{E}_{\text {hyst }}+\mathrm{E}_{\text {elast }}=\sum\left(\mathrm{F}_{\mathrm{i}} \cdot \text { lever-arm }\right) \cdot \Delta \theta_{\mathrm{i}}=\sum \mathrm{F}_{\mathrm{i}} \cdot\left(\Delta \theta_{\mathrm{i}} \cdot \text { lever-arm }\right)=\sum \mathrm{F}_{\mathrm{i}} \cdot \Delta \mathrm{u}_{\mathrm{i}}
$$

Where $F_{i}$ is the storey force and lever-arm is the distance between the storey and considered segment of the wall. The total energy may thus be calculated by integrating the storey forces with respect to the related relative displacements.

\section{10 Hysteretic energy from the different calculations}

The energy time-histories calculated with Eq. (8) and (9) for the first test of WDH5 are plotted in Fig. 15. The figure shows the good correspondence between the energy calculated with Eq. (9) and the input energy after subtraction of the friction energy, kinetic energy and the viscous damping energy $\left(\mathrm{E}_{\text {tot }}-\mathrm{E}_{\text {frict }}-\mathrm{E}_{\text {kin }}-\mathrm{E}_{\mathrm{D}}\right)$. Both energy time-histories join together at the end of the free vibrations when the friction force is equal to $\mathrm{R}=575 \mathrm{~N}(\mu=0.48 \%)$ in each storey. The friction forces were determined so that the input energy after subtraction of the energy dissipated by 
friction in the moveable storey masses and by viscous damping $\left(\mathrm{E}_{\text {tot }}-\mathrm{E}_{\text {frict }}-\mathrm{E}_{\mathrm{D}}\right)$ is equal to the hysteretic energy according to Eq. (9) at the end of the free vibrations. The friction coefficient $\mu$ may be thus determined. The friction coefficients calculated in this manner vary with the earthquake intensity and test wall and lie between $\mu=0.38 \%$ and $\mu=0.55 \%$ [3].

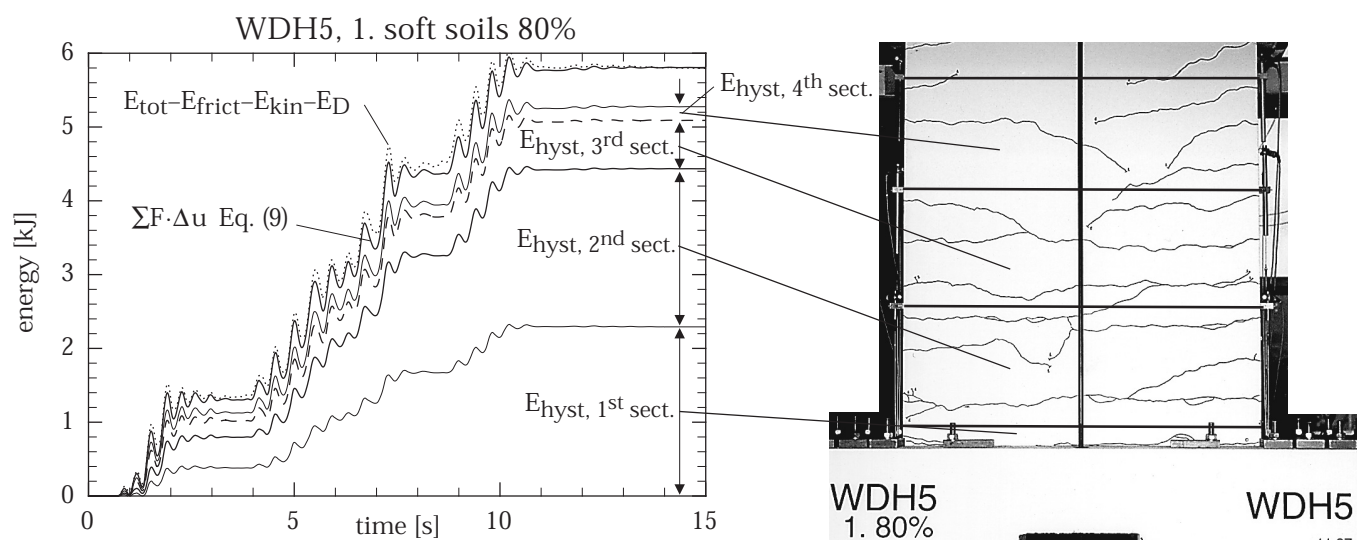

Fig. 15. WDH5 first test, hysteretic plus strain energy time-histories in the wall base. The different segment timehistories show the distribution of the energy dissipation in the wall base.

The values of the hysteretic plus the strain energy calculated by summing the energy in the four segments of the wall base ( $\left.\Sigma \mathrm{E}_{\text {hyst,i part }}\right)$ according to Eq. (8) and by using Eq. (9) show the same history (two upper solid lines in the Fig. 15). However they are different in size. The energy calculated by integrating the bending moments with respect to the segment rotations (Eq. (8)) in the wall base covers only a part of the effective energy. There are two reasons for that. Firstly, the variations of the bending moments and the rotations within the height of the wall segments were not considered. Secondly, the integral should be performed over the whole wall height to determine the entire energy. Only the rotations of the lowest four segments were considered by Eq. (8), whereas the rotations over the entire wall height were considered in Eq. (9). The energy calculated with Eq. (9) thus relates to the target value of the energy calculated with Eq. (8).

Fig. 15 also shows which energy fraction was dissipated in the different segments of the wall base. Approximately $44 \%$ of the energy was dissipated in the lowest segment. The segment stretches to about $60 \mathrm{~mm}$ above the wall footing and therefore includes in fact only the first crack above the wall footing. Approximately $84 \%$ of the energy was dissipated in the first two segments. The second segment is about $200 \mathrm{~mm}$ high. The remaining $16 \%$ of the hysteretic energy was dissipated above the second segment.

The different energy contents obtained by the end of each test are summarized in Table 7 . The tests in which wall failure occurs were not considered because the energy at the end of the test is in these cases of little significance.

\section{11 Discussion of the results}

The total input energy $\mathrm{E}_{\mathrm{tot}}(\mathrm{t}=\infty)$ at the end of free vibrations is equal to the entire amount of energy dissipated during the tests $\mathrm{E}_{\text {frict }}(\mathrm{t}=\infty)+\mathrm{E}_{\mathrm{D}}(\mathrm{t}=\infty)+\mathrm{E}_{\text {hyst }}(\mathrm{t}=\infty)$ because at this time the elastic and kinetic energy are zero. The two earthquakes used (Fig. 4 and 5) are significantly different in the total input energy. The earthquake for medium-stiff soils could only introduce approximately $5 \mathrm{~kJ}$ to wall WDH1 even at $120 \%$ (9. m 120\%). In contrast the earthquake for soft soils with $100 \%$ (2. s $100 \%$ ) could introduce more than $12 \mathrm{~kJ}$ to wall WDH6. The total input energy also depends on the wall behavior. The earthquake for soft soils with $100 \%$ could introduce about 25\% more energy to walls WDH5 and WDH6 than to walls WDH3 and WDH4. 
Table 7

Parts of dissipated energy at the end of the tests

\begin{tabular}{|c|c|c|c|c|c|c|c|c|c|}
\hline Wall & test & earthquake & $\begin{array}{l}\mathrm{E}_{\mathrm{tot}}^{\mathrm{a}} \\
{[\mathrm{kJ}]}\end{array}$ & $\begin{array}{l}E_{\text {firit }}{ }^{b} \\
{[\mathrm{~kJ}]}\end{array}$ & $\begin{array}{l}\mathrm{E}_{\mathrm{D}}{ }^{\mathrm{c}} \\
{[\mathrm{kJ}]}\end{array}$ & $\begin{array}{l}E_{\text {hyst }}^{d} \\
{[\mathrm{~kJ}]}\end{array}$ & $\begin{array}{c}\Delta \mathrm{E}_{2, \mathrm{hyst}} \mathrm{e} \\
{[\%]}\end{array}$ & $\begin{array}{c}\Delta \mathrm{E}_{1, \mathrm{hyst}}^{\mathrm{f}} \\
{[\%]}\end{array}$ & $\begin{array}{c}E_{\text {hys }} / E_{\text {lot }} \\
{[-]}\end{array}$ \\
\hline \multirow[t]{8}{*}{ WDH1 } & 1 & $\mathrm{~m} 20 \%$ & 0.53 & 0.26 & 0.07 & 0.20 & 69 & 48 & 0.39 \\
\hline & 2 & $\mathrm{~m} 40 \%$ & 1.67 & 0.43 & 0.37 & 0.88 & 70 & 54 & 0.53 \\
\hline & 3 & $\mathrm{~m} 70 \%$ & 3.56 & 0.68 & 0.56 & 2.32 & 93 & 78 & 0.65 \\
\hline & 4 & m $100 \%$ & 4.22 & 0.99 & 0.53 & 2.70 & 97 & 83 & 0.64 \\
\hline & 5 & m $100 \%$ & 3.88 & 0.96 & 0.50 & 2.41 & 96 & 82 & 0.62 \\
\hline & 7 & m $100 \%$ & 3.70 & 0.84 & 0.79 & 2.08 & 94 & 76 & 0.56 \\
\hline & 8 & $\mathrm{~m} 100 \%$ & 3.68 & 1.12 & 0.53 & 2.02 & 94 & 79 & 0.55 \\
\hline & 9 & m $120 \%$ & 5.02 & 1.61 & 0.64 & 2.77 & 96 & 81 & 0.55 \\
\hline WDH3 & 1 & s $100 \%$ & 9.77 & 1.97 & 0.94 & 6.86 & 86 & 60 & 0.70 \\
\hline \multirow[t]{2}{*}{ WDH4 } & 1 & s $80 \%$ & 7.86 & 1.67 & 0.76 & 5.44 & 83 & 41 & 0.69 \\
\hline & 2 & s $100 \%$ & 9.27 & 1.72 & 1.07 & 6.49 & 88 & 48 & 0.70 \\
\hline \multirow[t]{2}{*}{ WDH5 } & 1 & s $80 \%$ & 8.59 & 1.80 & 0.98 & 5.81 & 84 & 44 & 0.68 \\
\hline & 2 & s $100 \%$ & 12.11 & 1.93 & 1.45 & 8.72 & 86 & 44 & 0.72 \\
\hline \multirow[t]{2}{*}{ WDH6 } & 1 & s $80 \%$ & 8.35 & 1.44 & 1.01 & 5.90 & 86 & 57 & 0.71 \\
\hline & 2 & s $100 \%$ & 12.21 & 1.77 & 1.47 & 8.97 & 90 & 61 & 0.73 \\
\hline
\end{tabular}

${ }^{a} E_{\text {to: }}$ total input energy

${ }^{b} E_{\text {finct }}$ : energy dissipated by friction of the moveable storey masses

${ }^{c} E_{D}$ : energy dissipated by viscous damping

${ }^{d} E_{\text {hyst: }}$ energy dissipated by plastic deformations

${ }^{e} \Delta \mathrm{E}_{2, \text { hys: }}$ : portion of $\mathrm{E}_{\text {hyst }}$ till the 2 segment of the wall base (from $0 \mathrm{~mm}$ till $300 \mathrm{~mm}$ above the wall footing)

${ }^{\mathrm{f}} \Delta \mathrm{E}_{1, \text { hys: }}$ portion of $\mathrm{E}_{\text {hyst }}$ in the 1 segment of the wall base (from $0 \mathrm{~mm}$ till $60 \mathrm{~mm}$ above the wall footing)

WDH3 and WDH4 had a smaller flexural strength than WDH5 and WDH6 and showed therefore a more plastic behavior.

The lowest two segments of the wall base dissipate nearly $90 \%$ of the entire hysteretic energy $\left(\Delta \mathrm{E}_{2, \text { hyst }}\right)$. This proportion was reduced to approximately $70 \%$ for wall WDH1 at small earthquake intensities (1. m $20 \%$ and $2 . \mathrm{m} \mathrm{40 \% ).} \mathrm{The} \mathrm{lowest} \mathrm{two} \mathrm{segments} \mathrm{constituted} \mathrm{the} \mathrm{wall}$ base up to a height of approximately $300 \mathrm{~mm}$ above the top of the footing. The main part of the hysteretic energy was thus dissipated up to a height of about $30 \%$ of the horizontal wall length above the wall footing. The different walls barely show differences on this issue.

If only the lowest segment is considered $\left(\Delta \mathrm{E}_{1, \mathrm{hys}}\right)$, a pronounced difference appears in the wall behavior. The lowest segment contains practically only the lowest crack up to a height of about $60 \mathrm{~mm}$ above the wall footing. In WDH1 this segment dissipated approximately $80 \%$ of the entire hysteretic energy. By contrast only $40 \%$ to $60 \%$ was dissipated in this segment in walls WDH3 to WDH6. The energy dissipation for WDH1 was thus concentrated at the lowest crack. By contrast it was better distributed over the height in the other walls, which led to an improved seismic behavior. The difference may be related to the use of a reinforcement steel with superior ductility properties (higher strain hardening ratio) for the walls WDH3 to WDH6 than for WDH1 [20].

The ratio of the hysteretic energy to the total dissipated energy $\left(\mathrm{E}_{\text {hyst }} / \mathrm{E}_{\text {tot }}\right)$ at the end of the free vibrations is an important parameter. Generally it has only a small variation [18], [19]. The results in the Table 7 confirm this. The ratio was approximately $\mathrm{E}_{\text {hyst }} / \mathrm{E}_{\text {tot }}=0.6$ for WDH1 with the earthquake for medium-stiff soils and approximately $\mathrm{E}_{\text {hyst }} / \mathrm{E}_{\text {tot }}=0.7$ for the other walls with the earthquake for soft soils. However the tests on wall WDH1 with the higher earthquake intensities show a slight, steady decreasing ratio. Starting from $E_{\text {hyst }} / E_{\text {tot }}=0.65$ for test 3 the ratio dropped to $\mathrm{E}_{\text {hyst }} / \mathrm{E}_{\text {tot }}=0.55$ for test 9 . The ratio decrease is due to the modification in the wall behavior due to damage. The differences for small earthquake intensities ( $\mathrm{m} \mathrm{20 \%}$ and $\mathrm{m} \mathrm{40 \% )}$ are due to the preponderant friction of the moveable storey masses in comparison with the viscous damping. 


\section{Conclusions}

Based on the results of dynamic tests on six reinforced structural walls on the ETH earthquake simulator, the assessment of displacement ductility and energy leads to the following conclusions:

A) Significance for experimental interpretations

- Yield displacement can be directly determined from the test results. The change in wall behavior in the neighbourhood of yield displacement is evident when the relative displacements at the wall top are plotted as a function of the vertical displacements of a point at the wall base. The change in the wall behavior is detected by a slope variation in the tangent of the hysteretic loops. The location of the slope variation corresponds to the effective yield displacement. Measured values coincide well with the calculated ones. Even if this method does not enable the determination of the yield displacement with great precision, it does have an advantage in so far as that it may also be used with a wall that has already been damaged.

- Test results confirm that the ratio of the hysteretic energy to the total dissipated energy at the end of the test $\left(\mathrm{E}_{\text {hyst }} / \mathrm{E}_{\text {tot }}\right)$ is almost constant. Although the input energy is different (more than $240 \%$ ) for both the earthquakes used in the tests (and in addition intensities were varied), the ratio remained constant. The ratio was approximately $\mathrm{E}_{\text {hyst }} / \mathrm{E}_{\text {tot }}=0.6$ for an earthquake for medium-stiff soils and approximately $\mathrm{E}_{\text {hyst }} / \mathrm{E}_{\text {tot }}=0.7$ for an earthquake for soft soils.

B) Significance for design

- The test results confirm the design assumptions. Displacement ductilities agree well with assumed values. However, the displacement ductilities reached always lie slightly below the values of the strength reduction factors used. Difference can be explained by inherent safety margin of the equivalent force method employed in the design.

- Test results demonstrate that the ductility properties of steel is of primary importance. Seismic behavior is controlled by the distribution of the energy dissipation at the wall base. Although nearly $90 \%$ of the energy dissipated by plastic deformations $\left(\mathrm{E}_{\mathrm{hys}}\right)$ was, for all walls, dissipated within a height of about $30 \%$ of the horizontal wall length above the wall footing, the largest difference is attributed to energy dissipated in the lowest crack. Already $80 \%$ of $\mathrm{E}_{\text {hyst }}$ was dissipated in the first crack above the wall footing in cases of poor observed seismic behavior (limited displacement ductility). In contrast only about $50 \%$ of $\mathrm{E}_{\text {hyst }}$ was dissipated in the lowest crack in the case of good seismic behavior (large displacement ductility). The energy dissipation was consequently better distributed over the height of the plastic region. The difference is due to the use of a more ductile reinforcing steel (higher strain hardening ratio).

\section{Acknowledgements}

The research project presented in this paper was carried out at the Institute of Structural Engineering of the Swiss Federal Institute of Technology (ETH) Zürich and was funded by the "Stiftung für systematische wissenschaftliche Forschung auf dem Gebiet des Beton- und Stahlbetonbaus", of the "Vereins Schweizerischer Zement-, Kalk- und Gipsfabrikanten (VSZKGF)" and the Commission for Technology and Innovation.

\section{References}

[1] Lestuzzi P, Wenk T., Bachmann H. Dynamische Versuche an Stahlbetontragwänden auf dem ETH-Erdbebensimulator. Institut für Baustatik und Konstruktion (IBK), ETH Zürich. Bericht No. 240, ISBN 3-7643-6162-X. Birkhäuser Verlag, Basel 1999. 
[2] Bachmann H., Dazio A., Lestuzzi P. Developments in the Seismic Design of Buildings with RC Structural Walls. Proceedings of the 11th European Conference on Earthquake Engineering, September 6-11, 1998, CNIT, Paris la Défense, France.

[3] Lestuzzi P. Dynamisches plastisches Verhalten von Stahlbetontragwänden unter Erdbebeneinwirkung. Dissertation ETH Nr. 13726, Zürich 2000.

[4] Lestuzzi P. Effective Stiffness of RC Structural Walls in Dynamic Tests. Proceedings of the 12th European Conference on Earthquake Engineering, London, 2002. Paper Reference 861.

[5] Lestuzzi P., Badoux M. An Experimental Confirmation of the Equal Displacement Rule for RC Structural Walls. Proceedings of the fib-Symposium; Concrete Structures in Seismic Regions, Athens, 2003.

[6] Dazio A., Wenk T., Bachmann H. Vorversuche an einer Stahlbetontragwand auf dem ETHRütteltisch. Institut für Baustatik und Konstruktion (IBK), ETH Zürich. Bericht No. 213, ISBN 3-7643-5373-2. Birkhäuser Verlag, Basel 1995.

[7] Bachmann H., Wenk T., Baumann M., Lestuzzi P. Der neue ETH-Erdbebensimulator. Schweizer Ingenieur und Architekt SI+A, Heft 4/99, Zürich 1999.

[8] Bachmann H. Erdbebensicherung von Bauwerken. Birkhäuser Verlag, Basel 1995.

[9] SIA 162 (Norm). Betonbauten. Schweiz. Ingenieur- und Architekten-Verein. Zürich 1993.

[10] Gasparini D. A., Vanmarcke E. H. Simulated earthquake motions compatible with prescribed response spectra. MIT Civil Engineering Research Report R76-4 . Massachusetts Institute of Technology, Cambridge, Mass., 1976.

[11] SIA 160 (Norm). Einwirkung auf Tragwerke. Schweiz. Ingenieur- und ArchitektenVerein. Zürich, 1989.

[12] Eurocode 8. Auslegung von Bauwerken gegen Erdbeben. Europäische Vornorm ENV 1998-1-1 bis 3 (SIA V 160.811 bis 813, Ausgabe 1998). Schweiz. Ingenieur- und Architekten- Verein. Zürich 1998.

[13] Paulay T., Priestley M.J.N. Seismic Design of Reinforced Concrete and Masonry Buildings. John Wiley \& Sons, New York 1992.

[14] Priestley M.J.N., Kowalsky M. J. Aspects of Drift and Ductility Capacity of Rectangular Cantilever Structural Walls. Bulletin of the New Zealand National Society for Earthquake Engineering. 1998.

[15] Park R., Paulay T. Reinforced Concrete Structures. John Wiley \& Sons, New York 1975.

[16] Bruneau M., Chia-Ming U., Whittaker A. Ductile Design of Steel Structures. McGrawHill, 1998.

[17] Chopra A. K. Dynamics of Structures. Prentice-Hall, Englewood Cliffs, New Jersey, 1995.

[18] Fajfar P., Vidic T. Consistent Inelastic Design Spectra: Hysteretic and Input Energy. Earthquake Engineering And Structural Dynamics, Vol. 23, 523-537 (1994).

[19] Nassar A.A., Krawinkler H. Seismic Demands for SDOF and MDOF Systems. Research Report, The John A. Blume Earthquake Engineering Center, Department of Civil Engineering, Stanford University, Stanford, California, Report No. 95, June 1991.

[20] Bachmann H. Problems Relevant to Poor Ductility Properties of European Reinforcing Steel. Proceedings of the 12th World Conference on Earthquake Engineering. Paper ID 0524. Auckland, New Zealand, 2000. 